\title{
1 Excitation-contraction coupling and its relation to synaptic dysfunction
}

\section{2 in Drosophila}

3

$4 \quad$ Kiel G. Ormerod ${ }^{1}$, Anthony E. Scibelli ${ }^{2}$, J. Troy Littleton ${ }^{1}$

$5 \quad{ }^{1}$ The Picower Institute for Learning and Memory and Department of Biology, Massachusetts

6 Institute of Technology, Cambridge, MA; ${ }^{2}$ Department of Biology, Tufts University, Medford, 7 MA.

8

9

10 Correspondence and requests for materials should be addressed to K.G.O. (kormerod@ mit.edu)

11

12 The authors declare no competing interests. 


\section{Abstract}

29 The Drosophila neuromuscular system is widely used to characterize synaptic development and 30 function. However, little is known about how specific synaptic deficits alter neuromuscular 31 transduction and muscle contractility that ultimately dictate behavioural output. Here we develop 32 a system for detailed characterization of excitation-contraction coupling at Drosophila larval 33 NMJs and demonstrate how specific synaptic and neuronal manipulations disrupt muscle 34 contractility. Muscle contraction force increases with motoneuron stimulation frequency and 35 duration, showing considerable plasticity between $5-40 \mathrm{~Hz}$, while saturating above $50 \mathrm{~Hz}$. 36 Temperature is negatively correlated with muscle performance and enhanced at lower 37 temperatures. A screen for modulators of muscle contractility led to the identification and 38 characterization of the molecular and cellular pathway by which a specific FMRFa peptide, 39 TPAEDFMRFa, increases muscle performance. These findings indicate Drosophila NMJs 40 provide a robust system to relate synaptic dysfunction to alterations in excitation-contraction 41 coupling. 


\section{Introduction}

Neuromuscular systems that regulate stereotyped motor behaviours are composed of multiple component parts that interact in a highly coordinated and synchronized fashion to control muscle contraction and displacement (Goulding, 2009; Selverston, 1980). Central pattern generators (CPGs) initiate stereotyped behaviours such as locomotion, feeding, and swimming (Katz and Frost, 1995; Schwarz et al., 2017). CPGs relay rhythmic output through interneurons to motoneurons, controlling the timing and magnitude of muscle contraction (Selverston, 2010). In turn, the peripheral nervous system (PNS) signals the dynamic state of the muscle back to the CPG to modulate circuit output (Singhania and Grueber, 2014). A large body of work on the composition and regulation of these component parts comes from invertebrate studies in crayfish, leech, locust, crab, lamprey and others (Marder et al., 2005; Marder and Bucher, 2007; Nusbaum et al., 2017). Drosophila melanogaster has become a popular system to dissect and explore the composition and regulation of many of these components, including CPGs (Clark et al., 2018; Song et al., 2007), interneurons (Hasegawa et al., 2016), and sensory neurons (Singhania and Grueber, 2014; Song et al., 2007). Despite these efforts, studies directly examining the role of excitation-contraction coupling in locomotion are limited (Lehmann and Dickinson, 1997; Ormerod et al., 2018, 2016, 2015).

Locomotion is one of the most well studied rhythmic behaviours, including in Drosophila (Caldwell et al., 2003; Cheng et al., 2010; Clark et al., 2018; Hughes and Thomas, 2007; types of movements (e.g. turning, rolling, burrowing) but motivated linear crawling is the most highly stereotyped and orchestrated repetitive patterned motor behaviour produced from identical contraction waves (Heckscher et al., 2012; Hughes and Thomas, 2007). Muscles directly below the cuticle contract, then relax, to propagate peristaltic contraction waves from the posterior to the anterior of the larvae. These peristaltic waves are achieved by systematic, coordinated contractions of bodywall muscles, predominately those in the abdominal segments (Clark et al, 2018). Drosophila larvae are bilaterally symmetrical with stereotyped abdominal hemisegments composed of 30 individual muscle fibers. Each muscle is a viscerally-located, supercontractile (contracting to a length less than $50 \%$ of resting length) striated multinucleated muscle fiber 
81 Canonical muscle fiber contractility is controlled via postsynaptic glutamate receptors activated 82 by glutamate released from presynaptic motoneuron terminals (Harris and Littleton, 2015). 83 Approximately 36 motoneurons per hemisegment innervate the abdominal musculature. Three 84 different motoneuron subtypes are present: type I, which releases glutamate from synaptic vesicles; type II, which predominantly contain large dense core vesicles (DCVs); and type III, which innervate muscle 12 and release insulin-like peptides (Budnik, 1996; Hoang and Chiba, 2001). The neuromuscular junction (NMJ) is a critical site of plasticity and can be controlled by neuromodulators released directly from motoneuron terminals or centrally into the open circulator system as hormones (Milakovic et al., 2014; Ormerod et al., 2018, 2013). Type I motor neurons are rhythmically active during waves of muscle contractions underlying forward and reverse locomotion (Newman et al., 2017). Motoneuron activity is dictated by the neuronal input received from descending interneurons, whose firing pattern is ultimately controlled by the locomotor CPGs within the ventral nerve cord (VNC) (Fox et al., 2006).

To dissect the relative contribution of excitation-contraction coupling on locomotion, we employed a force transducer with $10 \mu \mathrm{N}$ resolution and a unique motoneuron-stimulation paradigm to characterize the dynamic output of the neuromuscular system and how plasticity in synaptic function manifests in changes to muscle output. Synaptically-driven muscle force increases with stimulation frequency and duration, with increases in either component leading to increased force. However, increasing both factors ultimately causes saturation in muscle force. The most substantial plasticity in muscle contractility occurs between 5 and $40 \mathrm{~Hz}$ stimulation. We also examined how mutants in several critical synaptic proteins, including Synaptotagmin (SYT), Complexin (CPX), and Glass-bottom boat (GBB), alter muscle performance. In addition, we found that temperature has a critical effect on Drosophila muscle contraction. Using this force contraction assay, we screened potential modulators of muscle contractility and identified 105 the neuropeptide, TPAEDFMRFa, that increases muscle performance in a dose-dependent 106 manner. We characterized the effects of the FMRFa peptide on muscle contractility and defined components of the pathway though which it operates. These data directly relate synaptic function with excitation-contraction coupling, providing insights into how key synaptic proteins control not only neurotransmitter release and synapse development, but also how they contribute to muscle contractility. 
111

112

113

114

115

116

117

118

119

120

121

122

123

124

125

126

127

128

129

130

131

132

133

134

135

136

137

138

139

140

\section{Results:}

To explore the contractile properties of Drosophila $3^{\text {rd }}$ instar larval NMJs, muscle contractions were elicited in semi-intact preparations with the CNS removed. A force transducer with $10 \mu \mathrm{N}$ resolution was modified to attach to the posterior end of a larvae (Figure 1A). Previous studies in Drosophila examined contractile properties by continually stimulating motoneurons at the same intraburst frequency and duration (Ormerod et al., 2016). An example of a single contraction induced from the setup, highlighting the amplitude, rise tau, and decay tau is shown in Figure 1B. To systematically characterize muscle contraction performance, bodywall contractions were induced by stimulating motoneurons at a frequency within the physiological range of $40 \mathrm{~Hz}$ for $600 \mathrm{~ms}$ duration every $15 \mathrm{~s}(0.067 \mathrm{~Hz})$ for up to an hour. Muscle responses were robust with steady-state contractions recorded after 1 hour showing a $29.2 \pm 9.6 \%$ reduction in force over this period (Figure 1C, N=10). Endogenous muscle contractions are driven by neuronal input whose firing pattern is ultimately controlled by the locomotor CPGs within the ventral nerve cord (Song et al, 2007). We recorded fictive locomotor patterns within motoneurons encoded from the CPGs from bodywall muscles via intracellular recordings from semi-intact preparations with the CNS and VNC left intact (Figure 1D). These patterned outputs displayed widely varying intraburst frequencies from 1 to $150 \mathrm{~Hz}$. Given this variable endogenous activity, we explored a more dynamic approach to eliciting muscle contractions to determine the range of muscle force bodywall muscles are capable of producing under a variety of motoneuron stimulation frequencies.

Initially, 25 impulses were delivered to motoneurons and the stimulation frequency was varied from 1 to $150 \mathrm{~Hz}$. For each experiment, 6 replicate contractions were induced at each stimulation frequency, followed by the next stimulation frequency, et cetera (Figure 1E). Contractions were averaged across the 6 replicate stimuli for a given stimulation frequency and the resulting trace with 95\% confidence interval (CI) was determined (Figure 1F). A forcefrequency curve of the force generated from this stimulation paradigm was then plotted as a percentage of the magnitude of force generated at the highest stimulation frequency of $150 \mathrm{~Hz}$ (Figure 1I, N=8). 25 stimuli at $1 \mathrm{~Hz}$ stimulation induced $3.5 \pm 1.1 \%$ of the maximum force produced at $150 \mathrm{~Hz}$, while $2 \mathrm{~Hz}$ stimulation was sufficient to induce $5.2 \pm 1.1 \%$ of the maximum force. Force generation at $2 \mathrm{~Hz}$ was not significantly greater than $1 \mathrm{~Hz}$ stimulation. In contrast, 
25 stimuli at $5 \mathrm{~Hz}$ produced a resultant force of $11.0 \pm 1.1 \%$ of the force at $150 \mathrm{~Hz}$, indicating this stimulation frequency is sufficient for temporal summation for contractile force. From 10 to $50 \mathrm{~Hz}$ stimulation, a nearly linear increase in force was produced at each successive increase in frequency $(10,15,20,25,30,40,50 \mathrm{~Hz})$, producing a maximal force at $50 \mathrm{~Hz}$. Increasing the stimulation frequency beyond $50 \mathrm{~Hz}$ resulted in a reduction in force production. Therefore, when total stimuli number remains constant, increasing stimulation frequency increases force production until saturation is reached at $50 \mathrm{~Hz}$.

Although $50 \mathrm{~Hz}$ drove maximal muscle contraction, it was unclear whether this saturation of force generation was a consequence of the stimulus frequency or stimulus duration. To explore this relationship further, burst duration was held constant at $600 \mathrm{~ms}$ and the frequency of stimulation was varied from 1 to $150 \mathrm{~Hz}$. Figure $1 \mathrm{G}$ depicts the raw data from each individual contraction within a single trial, and Figure $1 \mathrm{~F}$ depicts averaged traces from the replicate stimuli at a given stimulation frequency with a corresponding 95\% CI. Under these conditions, $5 \mathrm{~Hz}$ stimulation produced a force of $6.0 \pm 3.1 \%$ of that produced during $150 \mathrm{~Hz}$ stimulation (Table 1). Comparable to the previous experiment, force production increased in a linear fashion as the frequency increased from 10-50 Hz. However, increasing stimulation frequency to 100 and 150 $\mathrm{Hz}$ increased the force. Thus, both the duration and frequency of stimulation are critical factors in determining the absolute magnitude of force production.

To more fully explore the relationship between stimulus frequency and stimulus duration, we generated a series of force-frequency curves by keeping the burst duration constant through an entire experiment over 200, 250, 300, 500, 600, 750, 900, 1000, 2000, or 5000 ms while increasing stimulation frequency from 1 to $150 \mathrm{~Hz}$. Each of the independent force-frequency curves for a given burst duration generated a sigmoidal curve similar to what was observed at $600 \mathrm{~ms}$ (Figure 2A and Table 1). The overall patterns from the stimulation force recordings revealed that increasing stimulus frequency or duration results in a progressive and gradual increase in muscle force production. In all experiments, a single action potential was sufficient to induce a contraction that was between 2.6 and $3.3 \%$ of the $150 \mathrm{~Hz}$ contraction force (note that 1 $\mathrm{Hz}$ stimulation at 1000, 2000, and $5000 \mathrm{~ms}$ corresponded to 2, 4, and 10 stimuli respectively). Stimulus durations of 200, 250, and $300 \mathrm{~ms}$ resulted in increased force production with increases in stimulus frequency that did not saturate until $150 \mathrm{~Hz}$ (Table 1). Stimulus durations of 600, 
171750,900 , and $1000 \mathrm{~ms}$ resulted in sigmoidal increases in force production with increases in 172 stimulus frequency that saturated at $100 \mathrm{~Hz}$. Increasing the stimulus duration to 2000 and 5000 $173 \mathrm{~ms}$ resulted in a saturation of force at 40 and $30 \mathrm{~Hz}$, respectively. Given force saturates at or 174 above $100 \mathrm{~Hz}$ for all stimulus durations, there should be no differences between these conditions

175 176

177 178

179 180 181

182 once force reaches maximal. Thus, it is not surprising that the greatest differences between stimulus durations are seen from 10 to $50 \mathrm{~Hz}$, where considerable plasticity in muscle performance is still possible (Fig 2A). Plotting the percent differences between the various stimulation durations as a function of stimulus frequencies generated a bell-shaped curve with peak differences observed at $25 \mathrm{~Hz}$. The greatest effect of stimulus duration was observed at 25 $\mathrm{Hz}$, where an increase from 200 to $5000 \mathrm{~ms}$ resulted in a $70.3 \%$ increase in muscle force. Figure 2B depicts an overlay of $25 \mathrm{~Hz}$ stimulation from 200, 300, 600, 900, and $2000 \mathrm{~ms}$. A critical feature of the dataset is reflected in the stimulation frequency required to generate half-maximal force $(50 \%)$ for each stimulus duration, where a linear decrease in the stimulus frequency required to reach $50 \%$ is observed (Table 1). Plotting the 50\% max value as a function of stimulus duration generated a strong negative correlation $\left(\mathrm{R}^{2}=0.9\right)$ with a slope of -0.016 , indicating that every $100 \mathrm{~ms}$ increase in duration shifts this value to the left by $1.6 \mathrm{~Hz}$. Despite the dramatic effects that stimulation duration has on force production below $50 \mathrm{~Hz}$, the saturated or maximum raw force generated from a $200 \mathrm{~ms}$ duration stimulus was not significant for any of the longer stimulus durations (Figure 2C, D). These findings indicate maximal force from Drosophila bodywall muscles can be generated by a $200 \mathrm{~ms}$ stimulus delivered at $100 \mathrm{~Hz}$.

Throughout the experiments there was variability in the total raw force generated from one preparation to the next (Fig 2C), differing in magnitude by up to 50\%. Given this variability, one potential contributor to the differences in force generation was larval size. To examine this variable, the length and width of 100 larvae was measured and the total force generated by each animal was determined by eliciting a $100 \mathrm{~Hz}$ stimulus for $600 \mathrm{~ms}$ (Figure 3). The larval force was then plotted against length, width, area, and volume to determine if these physical parameters correlated with overall force production. None of these metrics revealed a positive correlation with contractile force (Figure 3C, D), indicating larval size does not have a significant effect on the total force that is generated from $3^{\text {rd }}$ instar larval preparations (two-tailed Pearson's correlation; Width: $\mathrm{r}=0.01462, \mathrm{P}=0.8906$; length: $\mathrm{r}=-0.1246, \mathrm{P}=0.2391$ ). 
We next explored whether the recruitment of different muscle fibers altered muscle

202

203

204

205

206

207

208

209

210

211

212

213

214

215

216

217

218

219

220

221

222

223

224

225

226

227

228

229

230

231 performance or maximal force generation. To examine the contribution from distinct muscle groups, larvae were dissected in three different orientations: i) along the dorsal midline where ventral muscle fibers $6,7,12$, and 13 contribute predominately to longitudinal force production; ii) along the ventral midline where dorsal fibers $1,2,3$, and 4 contribute principally; or iii) a lateral incision where lateral fibers 3, 4, 12, and 13 contribute primarily (Figure 4A, B). All three larval orientations displayed nearly identical force-frequency curves (Figure 4C, D), indicating performance was not significantly different across distinct muscle groups (One-way ANOVA, $\mathrm{N}=8, \mathrm{P}>0.05$ ). In addition, maximum force generated from muscle contraction elicited by stimulation in each larval orientation was similar (Figure 4E, One-way ANOVA, N=8, $\mathrm{P}=0.17$ ).

It is well established that both external $\mathrm{Ca}^{2+}$ and $\mathrm{Mg}^{2+}$ have a profound effect on pre-and postsynaptic intracellular mechanisms that contribute to muscle force production (Jan and Jan, 1976). Two commonly used Drosophila salines, hemolymph-like saline 3 and 3.1 (HL3 and HL3.1, Macleod et al, 2002) which contain $20 \mathrm{mM}$ and $4 \mathrm{mM}$ external $\mathrm{Mg}^{2+}$ respectively, were used to determine the effects of $\mathrm{Mg}^{2+}$ on force production. Additionally, 7 different external calcium concentrations $\left(\left[\mathrm{Ca}^{2+}\right]_{\mathrm{o}}\right.$ ) were explored for each saline, along with 4 different forcefrequency stimulations durations (200, 300, 600, and $900 \mathrm{~ms}$, Figure 5). At $0.1 \mathrm{mM}\left[\mathrm{Ca}^{2+}\right]_{0}$, the highest frequency stimulation $(150 \mathrm{~Hz})$ at the longest examined duration $(900 \mathrm{~ms})$ was unable to induce a recordable contraction in HL3. In contrast, a detectable contraction was observed at 10 $\mathrm{Hz}$ stimulation in HL3.1 (Figure 5A). Omitting external $\left[\mathrm{Ca}^{2+}\right]$ resulted in no muscle contraction in either saline, even at the highest stimulation frequencies. Raising $\left[\mathrm{Ca}^{2+}\right]_{0}$ from 0.1 to $0.25 \mathrm{mM}$ was sufficient to induce contractions at higher stimulation frequencies and durations $(40-150 \mathrm{~Hz})$ in HL3 saline, although a profound difference remained between the two salines (Figure 5A). This force-frequency gap was also observed at $0.5 \mathrm{mM}\left[\mathrm{Ca}^{2+}\right]_{0}$, and contractions were inducible at even lower stimulation frequencies in HL3.1 (Figure 5A). At $1.0 \mathrm{mM}\left[\mathrm{Ca}^{2+}\right]_{\mathrm{o}}$, no statistical differences were observed between the two salines at 600 and $900 \mathrm{~ms}$ duration force-frequency curves, and only subtle differences were observed at 200 and $300 \mathrm{~ms}$ (Figure 5A). Increasing $\left[\mathrm{Ca}^{2+}\right]_{\mathrm{o}}$ further to 1.5 or $2.0 \mathrm{mM}$ resulted in no observable statistical differences between the two conditions. Figure 5B shows the effect of external $\mathrm{Ca}^{2+}$ and $\mathrm{Mg}^{2+}$ on the half-maximal (50\%) stimulation frequency across the entire data set. Plotting the maximal force generated at each $\left[\mathrm{Ca}^{2+}\right]_{\mathrm{o}}$ for each stimulus duration generated data similar to that observed in Table 1, where an 
232 increase in either factor resulted in enhanced force generation in HL3. Above $1 \mathrm{mM}\left[\mathrm{Ca}^{2+}\right]_{\mathrm{o}}$, 233 neither stimulus duration or increasing $\left[\mathrm{Ca}^{2+}\right]_{\mathrm{o}}$ affected maximal force, indicating saturation at these levels. A similar effect was observed for HL3.1, but only at 0.1 and $0.25 \mathrm{mM}\left[\mathrm{Ca}^{2+}\right]_{\mathrm{o}}$, as muscle force plateaued across all stimulus durations at and above $0.5 \mathrm{mM}[\mathrm{Ca}]_{\mathrm{o}}$. There was significant differences between the two salines at each stimulus frequency and $0.1,0.25$, and 0.5 $\mathrm{mM}\left[\mathrm{Ca}^{2+}\right]_{\mathrm{o}}$ between 15 and $50 \mathrm{~Hz}$. However, no significant differences between the total force generated was found between the two salines above $1.0 \mathrm{mM}\left[\mathrm{Ca}^{2+}\right]_{0}$. As such, the higher $\mathrm{Mg}^{2+}$ concentrations found in HL3 saline resulted in a robust reduction in muscle contractile force, consistent with elevated $\mathrm{Mg}^{2+}$ reducing $\mathrm{Ca}^{2+}$ entry into the presynaptic terminal.

To determine if the magnitude of contractions elicited from a single stimulus represented a sensitive read-out of synaptic activity, we compared data obtained from single stimuli to that from stronger stimulations. The size of single-stimulus induced contractions as a percentage of force at $150 \mathrm{~Hz}$ stimulation was unchanged across stimulus durations (Table 1). The amplitude of contractions induced from a single stimulus increased in a proportional manner with increases in external $\mathrm{Ca}^{2+}$ and saturated beyond $1.5 \mathrm{mM}$ in HL3.1 saline. While contractions elicited from single stimuli were not observed in HL3 saline until $1.0 \mathrm{mM}\left[\mathrm{Ca}^{2+}\right]_{\mathrm{o}}$, they increased proportionally from 1.0 to $2.0 \mathrm{mM}\left[\mathrm{Ca}^{2+}\right]_{\mathrm{o}}$ (Figure 5C-D). Similar proportionate increase in muscle excitability was observed in EJP recordings at the NMJ in HL3.1 saline (Figure 5E). These findings indicate contractions elicited from single stimuli, in addition to maximal force output, represent a robust mechanism to correlate synaptic function with the excitationcontraction coupling machinery.

To examine the effect of temperature on muscle performance in control larvae, contractions were generated using $600 \mathrm{~ms}$ duration bursts at $40 \mathrm{~Hz}$ every 15 seconds and plotted as a percentage of the force generated at room temperature $\left(22^{\circ} \mathrm{C}\right)$. Surprisingly, decreasing the temperature from $22^{\circ} \mathrm{C}$ to $16^{\circ} \mathrm{C}$ increased contraction force, with a peak increase of $29.4 \pm 4.9 \%$ observed at $17^{\circ} \mathrm{C}$ (Figure 6A). Increasing the temperature from $22^{\circ} \mathrm{C}$ to $39^{\circ} \mathrm{C}$ gradually decreased the force of contraction until a complete failure at $40 \mathrm{~Hz}$ was observed at and above $32^{\circ} \mathrm{C}$ in some preparations. Representative traces from a single trial showing the effects of temperature on muscle contraction are shown in Figure 6B. Calculating the Q10 within the negatively linear component of the graph (between $17^{\circ} \mathrm{C}$ and $27^{\circ} \mathrm{C}$ ) generates a value of 0.24 , 
262

263

264

265

266

267

268

269

270

271

272

273

274

275

276

277

278

279

280

281

282

283

284

285

286

287

288

289

290

291

292

accentuating this negative thermal dependence. Earlier experiments revealed that greater plasticity in muscle performance was observed when stimulating between 20 and $30 \mathrm{~Hz}$. Consequently, we repeated this experiment using $25 \mathrm{~Hz}$ to determine if temperature might have a more profound effect, particularly at lower temperature. Significant differences were observed at $15,16,19$, and $20^{\circ} \mathrm{C}$, indicating more substantial effects of temperature at lower stimulation frequencies (Figure 6C). Rearing animals at different temperatures, particularly ectothermic animals, has been shown to adapt various aspect of an animal's physiology, shifting their physiological efficiency closer to rearing temperatures (Bennett, 1985). Thus, we reared animals at 22,25 and $29^{\circ} \mathrm{C}$ to determine if muscle performance could be shifted rightward towards better performance at higher temperatures. No significant difference was observed in animals reared at distinct temperatures (Figure 6D), suggesting the muscle excitation-contraction machinery does not display temperature adaptation.

To examine how synaptic dysfunction might alter muscle contractile force, forcefrequency plots were generated for several mutations that impair presynaptic neurotransmitter release or synapse number in Drosophila larvae. The magnitude of muscle force production elicited by $150 \mathrm{~Hz}$ stimulation for $600 \mathrm{~ms}$ (Figure 7A) or in response to a single stimulation (Figure 7B) was determined for several distinct synaptic mutants. Mutations in the SNAREbinding protein CPX significantly reduce evoked synchronous synaptic vesicle release and dramatically enhance spontaneous mini release (Cho et al., 2015; Huntwork and Littleton, 2007; Jorquera et al., 2012). Consistent with a key role for synchronous synaptic vesicle release for contraction force, $c p x^{S H 1}$ null mutant larvae show a significant reduction in both maximal muscle contraction force and the force elicited from a single stimulus (Figure 7A, B). Mutations in Synaptotagmin 1 (SYT1), a presynaptic $\mathrm{Ca}^{2+}$ sensor for synaptic vesicle fusion, eliminates synchronous evoked release and enhances asynchronous fusion (Guan et al., 2017; Lee et al., 2013; Yoshihara and Littleton, 2002). The maximal force produced in syt1 null larvae was significantly reduced, even more substantially than in cpx mutants and consistent with the more severe defect in synchronous fusion in the absence of SYT1 (Figure 7A). Single stimuli were unable to generate contractions in syt1 null larvae (Figure 7B), indicating muscle contraction in the absence of SYT1 likely requires the enhanced release from presynaptic facilitation that is intact in these mutants (Guan et al., 2020). SYT4 is a SYT isoform that localizes to the postsynaptic NMJ compartment and regulates retrograde signaling to enhance short-term 
293

294

295

296

297

298

299

300

301

302

303

304

305

306

307

308

309

310

311

312

313

314

315

316

317

318

319

320

321

plasticity following high frequency stimulation (Barber et al., 2009; Harris et al., 2016; Yoshihara et al., 2005). Loss of SYT4 caused a significant reduction in maximum force generation after a high frequency stimulation, but did not disrupt muscle contraction force elicited by single stimuli (Figure 7A, B). The Drosophila Gbb protein, a bone morphogenic protein (BMP) homolog, regulates synaptic growth, with null mutations reducing the number of synaptic boutons and release sites at the larval NMJ (McCabe et al, 2003). Gbb null mutants showed a significant reduction in both maximal force production and single stimulus contraction force. Together, these data indicate both synaptic release properties and synapse number contribute to excitation-contraction coupling in Drosophila larvae (Figure 7A, B).

To explore pathways that regulate excitation-contraction coupling at the Drosophila NMJ, we assayed several potential modulators to examine their effects on muscle force production. Classical neuromodulators and neurotransmitters shown to affect muscle performance in other systems or in Drosophila were assayed. To initially screen these neuromodulators, a paradigm using steady-state $40 \mathrm{~Hz}$ stimulation for $600 \mathrm{~ms}$ with an interburst duration of $15 \mathrm{~s}$ was used as this stimulation generates robust muscle contractions but is below force saturation. Candidate neuromodulators were perfused onto larval preparations for 5 mins at the relatively high concentration of $10^{-5} \mathrm{M}$ or $10^{-6} \mathrm{M}$ to make sure any potential effects on contraction could be detected. Several neuromodulators failed to show any effect on steady-state muscle contraction force during stimulation, including $10^{-5} \mathrm{M}$ leucokinin, $10^{-5} \mathrm{M}$ gammaaminobutyric acid (GABA), $10^{-5} \mathrm{M}$ acetylcholine, $10^{-5} \mathrm{M}$ pituitary adenylate cyclase activating polypeptide (PACAP27), $10^{-5} \mathrm{M}$ histamine, and $10^{-5} \mathrm{M}$ dopamine (Figure 8A-F). In contrast, the TPAEDFMRFa peptide encoded by the FMRFa gene previously implicated in muscle performance (Hewes et al, 1998) robustly enhanced muscle contraction force. Exogenous application of $10^{-6} \mathrm{M}$ TPAEDFMRFa steadily increased the amplitude of muscle contractions, reaching a maximal effect after 5 min of perfusion that resulted in an average force increase of $29 \pm 6.4 \%$ (Figure 8G). A dose-response curve for enhanced muscle contractile force was generated by examining the effects of TPAEDFMRFa at $10^{-5} \mathrm{M}, 10^{-6} \mathrm{M}, 10^{-7} \mathrm{M}, 10^{-8} \mathrm{M}, 10^{-9} \mathrm{M}$, and $10^{-10} \mathrm{M}$ with 7 replicate animals for each concentration (Figure $8 \mathrm{H}$ ). Under these conditions, the $\left[\mathrm{EC}_{50}\right]$ of TPAEDFMRFa for enhancing muscle contraction was $5.38 \times 10^{-8} \mathrm{M}$ (Figure $8 \mathrm{H}$ ). 
To further characterize this neuromodulator, the same series of TPAEDFMRFa concentrations were applied using a dynamic force-frequency curve paradigm. Control recordings were conducted by running larvae through the stimulation protocol from $1-150 \mathrm{~Hz}$, waiting a period of $5 \mathrm{~min}$, then performing the same stimulation protocol a $2^{\text {nd }}$ time. For experimental trials, the neuropeptide was perfused in during the 5 min rest period between trials and throughout the entirety of the $2^{\text {nd }}$ stimulation period. The effects of TPAEDFMRFa on muscle force across each frequency and at each concentration are summarized in Figure 8I. At 40 $\mathrm{Hz}$, the $\left[\mathrm{EC}_{50}\right]$ was $2.1 \times 10^{-8} \mathrm{M}$ using the dynamic protocol (Figure $8 \mathrm{H}$ ). There were no statistical differences between TPAEDFMRFa concentrations at 100 and $150 \mathrm{~Hz}$ stimulation, although significant increases were observed at $50 \mathrm{~Hz}$ stimulation from $10^{-7}$ to $10^{-5} \mathrm{M}$. Surprisingly, stimulation frequency decreases contraction efficiency as TPAEDFMRFa concentration increases, peaking at $5 \mathrm{~Hz}$ where a nearly $200 \%$ increase in contraction force is observed at $10^{-5}$ and $10^{-6} \mathrm{M}$. Based on control conditions (Figure 2), we predicted that the peptide would exert the greatest effect between stimulation frequencies of 20 to $35 \mathrm{~Hz}$ where the contractile machinery is normally most sensitive to nerve output. In contrast, the effectiveness of the peptide increased as stimulation frequency decreased. $\mathrm{EC}_{50}$ values generated for each stimulation frequency revealed similar values in the 2.1 to $3.9 \times 10^{-8} \mathrm{M}$ range (supplemental table 1 ).

To begin elucidating the molecular pathway by which TPAEDFMRFa exerts its effects on contraction force, the UAS-GAL4 system was employed to knockdown the FMRFa receptor using UAS-RNAi against $F M R F a$ mRNA. The pan-neuronal driver Elav-GAL4 was used to express $F M R F a$ RNAi presynaptically in motoneurons and the muscle specific Mef2-GAL4 was used to drive the RNAi postsynaptically in muscles. Knocking down the FMRFa receptor either pre- or post-synaptically significantly reduced the ability of TPAEDFMRFa to enhance muscle contraction force (Figure 9A). Using both GAl4 drivers to simultaneously knockdown the FMRFa receptor pre- and post-synaptically resulted in an additive decrease in the ability of the peptide to enhance muscle contraction. However, TPAEDFMRFa was still able to partially increase contraction even when the FMRFa receptor was knocked down simultaneously with 349 both drivers. In addition to the FMRFa receptor, myosuppressin receptors have also been shown to mediate some behavioral effects for a different FMRFa peptide, DPKQDFMRFa (Klose et al. 2010). To determine if TPAEDFMRFa might also activate this pathway, the two myosuppressin

352 receptors encoded in the genome were targeted with independent RNAi lines to assay their 
353 involvement in TPAEDFMRF's ability to enhance muscle contraction. Pre- and post-synaptic 354 expression of RNAi against the Dromyosuppressin receptor 1 did not significantly reduce the 355 ability of the peptide to potentiate muscle contraction (Figure 9B). However, knockdown of 356 Dromyosuppressin receptor 2 with either Mef2-GAL4 or with both Mef2-GAL4 and Elav-GAL4 357 simultaneously significantly reduced the ability of TPAEDFMRFa to potentiate muscle 358 contraction force. Taken together, these results indicate the TPAEDFMRFa neuropeptide 359 enhances muscle contractions through activity in both pre- and post-synaptic compartments via 360 the FMRFa receptor and Dromyosuppressin receptor 2. 


\section{Discussion}

These data demonstrate that the excitation-contraction coupling machinery in Drosophila $3^{\text {rd }}$ instar larvae provides a valuable model for exploring and dissecting the component parts that contribute to neuromotor circuitry. Using a force transducer with $10 \mu \mathrm{N}$ resolution, we assayed the contribution of key biophysical, physiological, genetic and molecular parameters to muscle contractility. The force-frequency relationship in bodywall muscles was determined using a dynamic motoneuron stimulation paradigm to quantify the full range of muscle contractility, from threshold to saturation. Larval size and orientation did not influence muscle performance, although physiological saline composition, predominately magnesium and calcium concentrations, had a profound effect on muscle contractility. Several mutants that disrupt synchronous synaptic vesicle fusion, including $S y t 1$ and $C p x$, dramatically reduced the magnitude of muscle contractions over all stimulation frequencies. In addition, mutations in $G b b$ that reduce synapse number also decreased the overall force of contraction, suggesting both the strength of synaptic transmission and the number of release sites are important for generating muscle contractile force. Changes in temperature also profoundly impacted muscle performance, with subtle decreases in temperature leading to a $30 \%$ increase in muscle force. Increasing the temperature beyond $30^{\circ} \mathrm{C}$ resulted in a near complete loss of muscle force production. Many different conventional invertebrate neurotransmitter and neuromodulators were shown to have no impact on muscle performance. However, exogenous application of the neuropeptide TPAEDFMRFa led to a dose-dependent increase in muscle force by as much as $300 \%$. Genetically reducing the expression of the FMRFa and Myosuppressin 2 receptors significantly attenuated the potency of the peptide. Both pre- and post-synaptic mechanisms contributed to TPAEDFMRFa's capacity to enhance contraction force, suggesting it acts through multiple receptors and in both synaptic compartments to effect muscle output.

Our data indicate neither the size of $3^{\text {rd }}$ instar larvae nor the muscle subgroup examined had any significant effect on the maximal force production or biophysical properties of excitation-contraction coupling across the whole animal (Figures 3, 4). Although muscle architecture can impact force production (Burkholder et al., 1994; David et al., 2016), studies have shown that muscle length does not result in greater force production, but rather impacts contraction velocity (Forman et al., 1972). For some fibers, e.g. muscle fiber 6, a clear increase 
in the resting muscle width is observed, compared to its direct neighbor, muscle fiber 7 . It is interesting that a greater number of longitudinal muscles are likely present along the ventral axis of the larvae (Fig. 4, e.g. 6, 7, 12,13) compared to the dorsal axis (1, 2, 9, 10). Additionally, considerably more muscles lie along the ventral axis that are not directly longitudinal, but have insertion angles that would generate considerable forces along the longitudinal axis (e.g. 14, 15, $16,17,26,27,28,30)$ compared to the dorsal axis $(3,11,19,20)$. Thus, given substantially more muscle fibers contribute to longitudinal force production, it is possible that dorsally located muscles produce greater force.

Changes in external $\mathrm{Ca}^{2+}$ have a profound effect on neurotransmitter release, as release is proportional to the third to fourth power of $\mathrm{Ca}^{2+}$ entry (Augustine et al., 1987; Hille, 1985; Katz and Miledi, 1970). Increases in the concentration of external $\mathrm{Ca}^{2+}$ at the Drosophila NMJ have a sigmoidal relationship with excitatory junctional currents, saturating at $\sim 1.0 \mathrm{mM}$ (Roche et al., 2002; Rohrbough et al., 1999). Figure 5E demonstrates the dose-dependent effects of external $\mathrm{Ca}^{2+}$ on EJP amplitude, which saturate at $\sim 1.0 \mathrm{mM}$. Increasing external $\mathrm{Ca}^{2+}$ has nearly identical effects on muscle force production as on synaptic properties observed from electrophysiological recordings, showing a sigmoidal curve which saturates with $1.0 \mathrm{mM}$ external $\mathrm{Ca}^{2+}$ in Drosophila HL3.1 saline. This effect is also conserved when examining the force of contractions elicited from a single action potential in HL3.1 saline. Thus, the effects of external $\mathrm{Ca}^{2+}$ on synaptic physiology appear to couple in a 1:1 fashion with the contraction machinery.

The divalent cation magnesium $\left(\mathrm{Mg}^{2+}\right)$ readily moves throughs $\mathrm{Ca}^{2+-}$ channels and therefore competitively interacts with $\mathrm{Ca}^{2+}$ entry. $\mathrm{Mg}^{2+}$ also has greater electronegatively than $\mathrm{Ca}^{2+}$ and can directly block $\mathrm{Ca}^{2+}$ channels (Kuno and Takahashi, 1986). In Drosophila, Jan and Jan (1976) reported a significant change in quantal content following a $2 \mathrm{mM}$ shift in $\mathrm{Mg}^{2+}$ concentration in standard saline (from 2 to $4 \mathrm{mM}$ ), and similar effects were observed in mouse vas deferens (Bennett and Florin, 1975). We observed significant effects when increasing the external $\mathrm{Mg}^{2+}$ concentration from $4 \mathrm{mM}$ to $20 \mathrm{mM}$. At low external $\mathrm{Ca}^{2+}$ concentrations $(0.1$ $\mathrm{mM}$ ), contractions were not observed at any stimulation frequency or duration with $20 \mathrm{mM}$ $\mathrm{Mg}^{2+}$, compared to robust contractions observed in $4 \mathrm{mM} \mathrm{Mg}^{2+}$ (Fig 5A). A significant decrease in muscle force production was apparent in 0.25 and $0.5 \mathrm{mM}\left[\mathrm{Ca}^{2+}\right]_{\mathrm{o}}$ in $4 \mathrm{mM}$ vs. $20 \mathrm{mM}$ $\left[\mathrm{Mg}^{2+}\right]_{\mathrm{o}}$. Indeed, a significant difference was observed in the amplitude of contractions elicited 
423 from single action potentials at all $\mathrm{Ca}^{2+}$ concentrations investigated between the two Drosophila 424 salines (Fig 5C-D). While increasing external $\mathrm{Mg}^{2+}$ concentration has been shown to decrease 425 synaptic strength, $\mathrm{Mg}^{2+}$ is also known to have a strong effect on muscle cells. Current-clamp 426 recordings from L-type $\mathrm{Ca}^{2+}$ channels, similar to those found in Drosophila muscle cells, reveal a 427 significant reduction in $\mathrm{Ca}^{2+}$ current following modest increases in external $\mathrm{Mg}^{2+}$ concentrations 428 (Wang et al., 2004). Additionally, $\mathrm{Mg}^{2+}$ has been shown to impact the $\mathrm{SR} \mathrm{Ca}^{2+}$-content 429 (Launikonis and Stephenson, 2000), efficiency of the $\mathrm{Na}^{+} / \mathrm{Ca}^{2+}$ exchanger (Levitsky and 430 Takahashi, 2013), as well as the uptake efficiency of the $\mathrm{Ca}^{2+}$ ATPase pump located on the SR 431 (Michailova et al., 2004). Thus, the observed effects of $\mathrm{Mg}^{2+}$ may be a consequence of 432 presynaptic effects on $\mathrm{Ca}^{2+}$ channels, or numerous effects directly on muscle fiber machinery.

Feng et al. (2004) noted a gradual but significant reduction in the EJP amplitude with increases in temperature, ultimately resulting in the inability to elicit an EJP at $40-42^{\circ} \mathrm{C}$. Our results demonstrate that increasing temperature also gradually and significantly decreases the force of muscle contraction, ultimately resulting in the inability to elicit contraction between 34 and $39^{\circ} \mathrm{C}$ (Fig. 7). Action potential propagation in axons is known to be blocked at higher temperatures due to rapid gating dynamics of $\mathrm{Na}^{+}$channels, reducing positive charge influx during membrane depolarization (Westerfield et al, 1978). Changes in temperature also have a substantial effect on the amplitude and waveform of action potentials, with decreases in temperature increasing the amplitude of action potentials, and drastically slowing the rise time ( $\tau$-rise) and decay time ( $\tau$-decay) (Miller and Rinzel, 1981). Impulse propagation failure is thought to occur at regions of nonuniform morphology causing increases in capacitance, typical at axonal branch points and transitions zones from myelination to demyelination (Hille, 1985). Temperature and conduction velocity of APs in axons and muscles however are positively correlated (Miller and Rinzel, 1981). The temperature-dependent effects on EJP amplitude observed by Feng et al., (2004) appear to strongly correlate with the effects of temperature on muscle contraction dynamics observed here (Figure 7). Our results also found that the strength of muscle contractions increases with decreases in temperature, saturating at $17-18^{\circ} \mathrm{C}$. In addition, to the effects on axonal conduction properties, temperature may also affect multiple aspects of muscle contraction from membrane excitation (Vornanen, 2016), $\mathrm{Ca}^{2+-}$ dynamics from the SR (Abu-Amra et al., 2015; Shiels et al., 2002), $\mathrm{Ca}^{2+}$-dependent contraction activation (Ranatunga, 2018), and mechanisms of cross-bridge cycling (Wang and Kawai, 2001). While effects of 
temperature on synaptic efficacy appear to directly translate to the excitation-contraction coupling machinery, it is possible that temperature is also affecting multiple aspects of muscle biology.

To examine how defects in synaptic transmission and synapse number manifest onto excitation-contraction coupling, we quantified the force-frequency relationship for mutations in Syt1, Cpx , Gbb and Syt4. Loss of the $\mathrm{Ca}^{2+}$ sensor SYT1 caused a $100 \%$ and $84 \%$ reduction in the amplitude of single and maximal contractions, respectively, compared to a $90 \%$ reduction in EJC amplitude (Guan et al, 2017). Loss of CPX resulted in a $85 \%$ and $63 \%$ reduction in the amplitude of single and maximal contractions compared to a $75 \%$ reduction observed in EJP amplitude (Cho et al, 2015). These results indicate the effects of these mutations on evoked synaptic transmission relate directly to effects on the contraction machinery. Mutations in Syt4, which regulates retrograde signaling and short-term synaptic plasticity, caused a significant $24 \%$ decrease in the force of maximal contractions, but no effect on the amplitude of contractions elicited from single action potentials. A similar $20 \%$ reduction in EJC amplitude was also found in Syt4 mutants (Barber et al, 2009). Gbb mutants displayed a $80 \%$ and $55 \%$ decrease in contraction force for single stimuli and maximal contraction. Disruption of GBB signaling leads to a severe decrease in synapse number and a corresponding $70 \%$ decrease in EJP amplitude (McCabe et al, 2003). Overall, these data indicate whole larval bodywall force contraction assays provide a robust readout for synaptic dysfunction, with single contraction data closely matching previously reported defects in evoked release.

The NMJ of arthropods have long been explored as critical areas of influence by neuromodulatory substances (Robbins, 1959; Van Harreveld and Mendelson, 1959). Among the small classical neuromodulators, we assayed muscle contraction force changes following bath application of dopamine, histamine, acetylcholine and GABA. The biogenic amine dopamine has been shown to enhance synaptic efficacy and muscle contraction in numerous model systems, including the lobster (Lingle, 1981), Aplysia (Swann et al., 1982) and shrimp (Meyrand and Moulins, 1986). Additionally, dopamine has previously been shown to decrease EJP amplitude at Drosophila larval muscle 6 (Cooper and Neckameyer, 1999). However, we found no observable effect of dopamine on muscle contractions. Perhaps only subsets of muscle fibers are affected by dopamine, and the altered EJPs in these fibers is insufficient to generate a noticeable 
enhancement in muscle force production over the entire larval bodywall. Although histamine has been shown in modulate the force of contraction of smooth muscle and cardiac tissue (Chan, 1977; Reite, 1972), we found no effect on the Drosophila NMJ. Acetylcholine functions as the neurotransmitter at vertebrate NMJs, but can also serve as a neuromodulator (Picciotto et al., 2012). Exogenous application of acetylcholine had no effect on contraction force at the Drosophila glutamatergic NMJ. GABA is classically defined as the primary inhibitory neurotransmitter in the brain, but no evidence exists to suggest GABA receptors are present at the NMJ (Kravitz et al., 1963). Indeed, GABA had no effect on modulating force at the Drosophila NMJ. These observations suggest glutamate is likely to be the major small molecular effector at the fly NMJ.

Multiple neuropeptides have also been suggested to modulate the neuromuscular system. Landgraf et al, (2003) described leucokinin-immunoreactivity in type III terminals at the Drosophila NMJ, but we found no effect on contraction when leucokinin was exogenously applied to the dissected larval preparation. Pituitary adenylate cyclase activating polypeptide (PACAP) is encoded by the amnesiac gene in Drosophila. PACAP-38 has previously been shown to modulate $\mathrm{Ca}^{2+}$ channel dynamics and contraction in Drosophila $3^{\text {rd }}$ instar bodywall muscles (Bhattacharya et al., 2004; Zhong and Peña, 1995). We found that the shorter isoform, PACAP-27, had no effect on muscle contraction. The Drosophila genome encodes a single gene for the FMRF-like peptides, the $d F M R F$ amide gene which encodes 8 peptides. DPKQDFMRFa is the most abundantly encoded, with 5 replicate copies, and has been previously characterized at the Drosophila NMJ. DPKQDFMRFa is known to enhance synaptic transmission via the CaMKII pathway through the FMRFa receptor (Dunn and Mercier, 2005; Klose et al, 2010). DPKQDFMRFa increases nerve-evoked contractions and can also elicit contractions in the absence of the CNS (Hewes et al, 1998; Clark et al, 2008; Ormerod et al, 2015).

The second most abundant FMRFa-like peptide is TPAEDFMRFa with two replicate copies (Nambu et al, 1988; Schneider and Taghert, 1988). Previous work has shown that TPAEDFMRFa enhances twitch tension in a reduced preparation from Drosophila $3^{\text {rd }}$ instar larvae in a similar magnitude to DPKQDFMRFa (Hewes et al, 1998). To further examine this pathway for modulating neuromuscular contraction, we examined the effects of exogenous application of TPAEDFMRFa by eliciting contractions using $40 \mathrm{~Hz}$ stimulation. This paradigm 
revealed a robust increase in the amplitude of nerve-evoked contractions that did not wash out with 10 min of saline perfusion (Figure 8G). TPAEDFMRFa displayed an $\mathrm{EC}_{50}$ of $5.4 \times 10^{-8} \mathrm{M}$, generating a $20 \%$ increase in the amplitude of contractions to a maximal increase of $38 \%$ at $10^{-}$ ${ }^{6} \mathrm{M}$. By examining the effects of the peptide across a wide-range of stimulation frequencies from 1-150 Hz, TPAEDFMRF was much more effective at increasing contraction force at lower stimulation frequencies, with maximal effects observed at 5 and $10 \mathrm{~Hz}(189 \pm 28 \%$ and $156 \pm$ $10 \%$ respectively). Given each successive decrease in stimulation frequency elicited a greater amount of potentiation by the peptide, it is likely that the electrochemical driving force and biophysical properties inherent to the contractile machinery have the greatest potential for modulation at lower stimulation frequencies given they are the farthest from saturated. The lack of modulation at higher stimulation frequencies is likely a result of muscle contraction being at or near saturation. Thus, release of neuromodulatory substances like FMRFa peptides would maximize the amplitude of contractions, enabling larvae to generate a stronger contraction with less synaptic input. Release of the peptide could aid in the fight-or-flight response to enable larvae to reach maximal locomotor velocity or play a role in preventing synaptic fatigue under conditions of chronic neuromotor activation.

Using the UAS/GAL4 system to knockdown putative receptors mediating the effects of TPAEDFMRFa, we found a role for the FMRFa receptor in both pre-and postsynaptic compartments contributes to the peptide's ability to potentiate nerve-evoked contractions. However, using nerve and muscle-specific drivers simultaneously was insufficient to completely abolish the effect on contraction force. It is therefore likely that other receptors also contribute to the enhancement of nerve-evoked contractions by the peptide, or RNAi was insufficient to fully remove the FMRFa receptor. We tested knockdown of two myosuppressin receptors previously implicated in mediating the effects of DPKQDFMRFa (Klose et al, 2010). Myosuppressin receptor 1 appears to play no role in the enhancement of nerve-evoked contractions by TPAEDFMRFa. However, knocking down myosuppressin receptor 2 either postsynaptically, or pre and post-synaptically, significantly reduced the ability of the peptide to enhance contraction.

Taken together, our results demonstrate that Drosophila serves as a robust system to explore excitation-contraction coupling and dissect the component parts that contribute to neuromotor circuitry. Our characterization of the force-frequency components of contraction 
544 indicate Drosophila muscle contractile force is similar to force-frequency data obtained in other

545 vertebrate models (Eshima et al., 2017; Terry et al., 2014). Indeed, critical muscle genes

546 underlying the development and function of the musculature are highly conserved between

547 Drosophila and more commonly studied vertebrate species (Taylor, 2013). As such, Drosophila

548 larval bodywall muscles provide an excellent model for investigations of excitation-contraction

549 coupling and linking known synaptic defects in neuronal mutants to their final effect on muscle

550 force production. 


\section{Materials and methods}

554

555

556

557

558

559

560

561

562

563

564

565

566

567

568

569

570

571

572

573

574

575

576

577

578

579

580

581

\section{Drosophila stocks}

Drosophila melanogaster were cultured on standard medium at $21^{\circ} \mathrm{C}$ at constant humidity in a 12:12 light:dark cycle. Wandering $3^{\text {rd }}$ instar larvae of both sexes were used for experimentation. Canton S (CS) flies obtained from the Bloomington Drosophila stock center (BDSC) were used as controls except when noted. $G b b$ mutants $\left(G b b^{1} / G b b^{2}\right)$ was obtained from BDSC (McCabe et al., 2003). The remaining mutants examined included Cpx ${ }^{S H I}$ nulls (Huntwork and Littleton, 2007), Syt1 nulls (Syt ${ }^{N 13} / S y t 1^{A D 4}$ ) (Littleton et al., 1994) and Syt4 nulls $\left(S y t 4^{B A 1}\right)$ (Yoshihara et al., 2005). Other genotypes used in the study include: elav ${ }^{\text {C155-GAL4 }}$ (BDSC \#8765), Mhc-GAL4 (BDSC\#55132), FMRFa receptor RNAi (VDRC v9594), Dromyosuppressin receptor 1 RNA (VDRC v9369), Dromyosuppressin receptor 2 (VDRC v49952).

\section{Dissection}

Wandering $3^{\text {rd }}$ instar larvae were isolated from the sides of culture vials and dissected in modified hemolymph-like (HL3) saline. Two Drosophila salines were examined (Feng et al., 2004). The first Hemolymph-Like saline HL3 has the following composition (in mM): $\mathrm{NaCl}: 70$; $\mathrm{KCl}: 5 ; \mathrm{CaCl}_{2}: 1.5 ; \mathrm{MgCl}_{2}: 20 ; \mathrm{NaHCO}_{3}$ : 10; Trehalose: 5; Sucrose: 115; HEPES: 5, (pH = 7.18). The second saline, HL3.1, has the same composition but $\left[\mathrm{MgCl}_{2}\right]$ was reduced to $4 \mathrm{mM}$. Larvae were pinned dorsal side up at the anterior and posterior ends, a small incision was made along the entire dorsal midline and the visceral organs were removed. All nerves emerging from the central nervous system (CNS) were severed at the ventral nerve cord, and the CNS and ventral nerve cord were removed. In some experiments, the orientation of the larvae prior to initial dissection was altered depending on which muscles were examined. To examine the dorsal muscles, the animal was pinned ventral side up and dissected along the ventral midline. To examine the lateral muscles, the animal was pinned lateral side up (muscle fiber 4 at the apex) and dissected along the lateral most point.

\section{Electrophysiology}


Excitatory junctional potentials (EJPs) were elicited by stimulating severed abdominal

583

584

585

586

587

588

589

590

591

592

593

594

595

596

597

598

599

600

601

602

603

604

605

606

607

608

609

nerves. A Master 8 A.M.P.I. (Jerusalem, Israel) stimulator was used to elicit stimulation via a suction electrode (A-M systems, Sequim, WA). EJPs were recorded using sharp glass microelectrodes containing a 2:1 mixture of $3 \mathrm{M}$ potassium chloride:3 $\mathrm{M}$ potassium acetate, with an electrode resistance of 40-80 M $\Omega$. An Axoclamp 2B amplifier (Molecular Devices, San Jose, CA) was used for signal detection and digitized via Axon Instruments digidata 1550 (Molecular Devices). Signals were acquired at $10 \mathrm{kHz}$ using Clampex and processed using Clampfit and MiniAnalysis.

\section{Nerve-evoked Contraction Force Recordings}

All force recordings were obtained using the Aurora Scientific 403A force transducer system (Aurora Scientific, Aurora, Canada), including the force transducer headstage, an amplifier, and digitizer. Nerve-evoked contractions were generated using bursts of electrical stimuli from a Master 8 (A.M.P.I.) stimulator. The duration of single impulses was $5 \times 10^{-4} \mathrm{~s}$ and the interburst duration was kept constant at $15 \mathrm{~s}$. Burst duration and frequency were altered for each individual experiment. Larvae were dissected as outlined above. To attach larvae to the force transducer, a hook was made from a fine minuten pin and placed onto the posterior end of the larvae. Digitized data was acquired using Aurora Scientific software, Dynamic Muscle Acquisition Software (DMCv5.5). The digitized data was imported and processed in Matlab using custom code written by A. Scibelli (available on request). Temperature was controlled using a CL-200A heater-cooler controller (Warner Instruments, Hamden CT) with a heat sink (Koolance) that regulates temperature via feedback from a thermocouple placed directly next to the animal to enable control within $0.1{ }^{\circ} \mathrm{C}$. Temperature was rapidly modified by constant perfusion of physiological saline though a Harvard apparatus in-line saline temperature controller (Holliston, MA) and a Warner Instruments dish temperature regulator (Model TB3 CCD). 
Histamine hydrochloride (H7250, Sigma, St. Louis, MO), dopamine hydrochloride 611 (H8502, Sigma), PACAP27 amide, Ovine (2151, Sigma), GABA (A2129, Sigma), Acetylcholine

612 chloride (A6626, Sigma). Leucokinin (NSVVLGKKQRFHSWG) and TPAEDFMRFa were 613 custom synthesized from Genscript (Piscataway, NJ) with a $>98 \%$ purity.

\section{Acknowledgements}

616 This work was supported by NIH grant NS40296 to J.T.L and a postdoctoral research fellowship 617 from Natural Science and Engineering Research Council of Canada to KGO. We thank the 618 Bloomington Drosophila Stock Center (NIH P40OD018537) for Drosophila stocks and members 619 of the Littleton lab for helpful discussions and comments on the manuscript.

620

621

622

623

624

625 


\section{References:}

Abu-Amra E-S, El-Sayed MF, Badr A. 2015. Temperature dependence of cardiac sarcoplasmic reticulum and sarcolemma in the ventricle of catfish (Clarias gariepinus). J Basic Appl Zool 72:89-95. doi:10.1016/j.jobaz.2015.05.004

Augustine GJ, Charlton MP, Smith SJ. 1987. Cacium action in synaptic transmitter release.

Barber CF, Jorquera RA, Melom JE, Littleton JT. 2009. Postsynaptic regulation of synaptic plasticity by synaptotagmin 4 requires both C2 domains. J Cell Biol 187:295-310. doi:10.1083/jcb.200903098

Bennett AF. 1985. Temperature and muscle. J Exp Biol 115.

Bennett MR, Florin T. 1975. An electrophysiological analysis of the effect of Ca ions on neuromuscular transmission in the mose vas deferens, Br. J. Pharmac.

Bhattacharya A, Lakhman SS, Singh S. 2004. Modulation of L-type calcium channels in Drosophila via a pituitary adenylyl cyclase-activating polypeptide (PACAP)-mediated pathway. J Biol Chem 279:37291-37297. doi:10.1074/jbc.M403819200

Budnik V. 1996. Synapse maturation and structural plasticity at Drosophila neuromuscular junctions. Curr Opin Neurobiol 6:858-67. doi:10.1016/s0959-4388(96)80038-9

Burkholder TJ, Fingado B, Baron S, Lieber RL. 1994. Relationship Between Muscle Fiber Types and Sizes and Muscle Architectural Properties in the Mouse Hindlimb, JOURNAL OF MORPHOLOGY.

Caldwell JC, Miller MM, Wing S, Soll DR, Eberl DF. 2003. Dynamic analysis of larval locomotion in Drosophila chordotonal organ mutants. Proc Natl Acad Sci U S A 100:16053-8. doi:10.1073/pnas.2535546100

Chan DKO. 1977. Comparative Physiology of the Vasomotor Effects of Neurohypophysial Peptides in the Vertebrates.

Cheng LE, Song W, Looger LL, Jan LY, Jan YN. 2010. The role of the TRP channel NompC in Drosophila larval and adult locomotion. Neuron 67:373-80. 
doi:10.1016/j.neuron.2010.07.004

653

654

655

656

657

658

659

660

661

662

663

664

665

666

667

668

669

670

671

672

673

674

675

676

677

678

Cho RW, Buhl LK, Volfson D, Tran A, Li F, Akbergenova Y, Littleton JT. 2015. Phosphorylation of Complexin by PKA Regulates Activity-Dependent Spontaneous Neurotransmitter Release and Structural Synaptic Plasticity. Neuron 88:749-761. doi:10.1016/j.neuron.2015.10.011

Clark MQ, Zarin AA, Carreira-Rosario A, Doe CQ. 2018. Neural circuits driving larval locomotion in Drosophila. Neural Dev. doi:10.1186/s13064-018-0103-z

Cooper RL, Neckameyer WS. 1999. Dopaminergic modulation of motor neuron activity and neuromuscular function in Drosophila melanogaster, Comparative Biochemistry and Physiology Part B.

David S, Funken J, Potthast W, Blanke A. 2016. Musculoskeletal modelling under an evolutionary perspective: Deciphering the role of single muscle regions in closely related insects. J R Soc Interface 13. doi:10.1098/rsif.2016.0675

Eshima H, Tamura Y, Kakehi S, Kurebayashi N, Murayama T, Nakamura K, Kakigi R, Okada T, Sakurai T, Kawamori R, Watada H. 2017. Long-term, but not short-term high-fat diet induces fiber composition changes and impaired contractile force in mouse fast-twitch skeletal muscle. Physiol Rep 5:e13250. doi:10.14814/phy2.13250

Feng Y, Ueda A, Wu C-F. 2004. A modified minimal hemolymph-like solution, HL3.1, for physiological recordings at the neuromuscular junctions of normal and mutant drosophila larvae. J Neurogenet 18:377-402. doi:10.1080/01677060490894522

Forman R, Ford LE, Sonnenblick EH. 1972. Effect of Muscle Length on the Force-Velocity Relationship of Tetanized Cardiac Muscle, Circulation Riittreb.

Fox LE, Soll DR, Wu C-F. 2006. Coordination and modulation of locomotion pattern generators in Drosophila larvae: effects of altered biogenic amine levels by the tyramine beta hydroxlyase mutation. J Neurosci 26:1486-98. doi:10.1523/JNEUROSCI.4749-05.2006

Goulding M. 2009. Circuits controlling vertebrate locomotion: Moving in a new direction. Nat Rev Neurosci. doi:10.1038/nrn2608 
Guan Z, Bykhovskaia M, Jorquera RA, Sutton RB, Akbergenova Y, Littleton JT. 2017. A synaptotagmin suppressor screen indicates SNARE binding controls the timing and $\mathrm{Ca} 2+$ cooperativity of vesicle fusion. Elife 6. doi:10.7554/eLife.28409

Guan Z, Quiñones-Frías MC, Akbergenova Y, Littleton JT. 2020. Drosophila Synaptotagmin 7 negatively regulates synaptic vesicle release and replenishment in a dosage-dependent manner. Elife. doi:10.7554/eLife.55443

Harris KP, Littleton JT. 2015. Transmission, development, and plasticity of synapses. Genetics 201:345-375. doi:10.1534/genetics.115.176529

Harris KP, Zhang Y V, Piccioli ZD, Perrimon N, Littleton JT. 2016. The postsynaptic t-SNARE Syntaxin 4 controls traffic of Neuroligin 1 and Synaptotagmin 4 to regulate retrograde signaling. Elife 5. doi:10.7554/eLife.13881

Hasegawa E, Truman JW, Nose A. 2016. Identification of excitatory premotor interneurons which regulate local muscle contraction during Drosophila larval locomotion. Sci Rep 6. doi:10.1038/srep30806

Heckscher ES, Lockery SR, Doe CQ. 2012. Characterization of Drosophila larval crawling at the level of organism, segment, and somatic body wall musculature. J Neurosci 32:1246012471. doi:10.1523/JNEUROSCI.0222-12.2012

Hille B. 1985. Ionic channels of excitable membranes. Bertil Hille. Sunderland, Ma: Sinauer Associates, 1984. J Neurosci Res 13:599-600. doi:10.1002/jnr.490130415

Hoang B, Chiba A. 2001. Single-cell analysis of Drosophila larval neuromuscular synapses. Dev Biol 229:55-70. doi:10.1006/dbio.2000.9983

Hughes CL, Thomas JB. 2007. A sensory feedback circuit coordinates muscle activity in Drosophila. Mol Cell Neurosci 35:383-96. doi:10.1016/j.mcn.2007.04.001

Huntwork S, Littleton JT. 2007. A complexin fusion clamp regulates spontaneous neurotransmitter release and synaptic growth. Nat Neurosci 10:1235-7. doi:10.1038/nn1980

Jorquera RA, Huntwork-Rodriguez S, Akbergenova Y, Cho RW, Troy Littleton J. 2012. 
Complexin controls spontaneous and evoked neurotransmitter release by regulating the timing and properties of synaptotagmin activity. J Neurosci 32:18234-18245. doi:10.1523/JNEUROSCI.3212-12.2012

Katz B, Miledi R. 1970. Further study of the role of calcium in synaptic transmission. J Physiol 207:789-801. doi:10.1113/jphysiol.1970.sp009095

Katz PS, Frost WN. 1995. Intrinsic neuromodulation in the Tritonia swim CPG: Serotonin mediates both neuromodulation and neurotransmission by the dorsal swim interneurons. $J$ Neurophysiol 74:2281-2294. doi:10.1152/jn.1995.74.6.2281

Keshishian H, Broadie K, Chiba A, Bate M. 1996. The Drosophila Neuromuscular Junction: A Model System for Studying Synaptic Development and Function. Annu Rev Neurosci 19:545-575. doi:10.1146/annurev.ne.19.030196.002553

Koh YH, Gramates LS, Budnik V. 2000. Drosophila larval neuromuscular junction: Molecular components and mechanisms underlying synaptic plasticity. Microsc Res Tech 49:14-25. doi:10.1002/(SICI)1097-0029(20000401)49:1<14::AID-JEMT3>3.0.CO;2-G

Kravitz EA, Kuffler SW, Potter DD. 1963. Gamma-aminobutyric acid and other blocking compounds in crustacea III. Their relative concentrations in separated motor and inhitory axons. J Neurophysiol 26:739-751. doi:10.1152/jn.1963.26.5.739

Kuno M, Takahashi T. 1986. Effects of calcium and magnesium on transmitter release at Ia synapses of rat spinal motoneurones in vitro. J Physiol 376:543-553. doi:10.1113/jphysiol.1986.sp016169

Launikonis BS, Stephenson DG. 2000. Effects of $\mathrm{Mg} 2+$ on Ca2+ release from sarcoplasmic reticulum of skeletal muscle fibres from yabby (crustacean) and rat. J Physiol 526:299-312. doi:10.1111/j.1469-7793.2000.00299.x

Lee J, Guan Z, Akbergenova Y, Troy Littleton J. 2013. Genetic analysis of synaptotagmin C2 domain specificity in regulating spontaneous and evoked neurotransmitter release. $J$ Neurosci 33:187-200. doi:10.1523/JNEUROSCI.3214-12.2013 
during elevated force production in the fruit fly Drosophila melanogaster. J Exp Biol 200.

Levitsky DO, Takahashi M. 2013. Interplay of Ca2+ and Mg2+ in Sodium-Calcium Exchanger and in Other Ca2+-Binding Proteins: Magnesium, Watchdog That Blocks Each Turn if Able. pp. 65-78. doi:10.1007/978-1-4614-4756-6_7

Lingle C. 1981. The Modulatory Action of Dopamine on Crustacean Foregut Neuromuscular Preparations. J Exp Biol 94.

Littleton JT, Stern M, Perin M, Bellen HJ. 1994. Calcium dependence of neurotransmitter release and rate of spontaneous vesicle fusions are altered in Drosophila synaptotagmin mutants. Proc Natl Acad Sci U S A 91:10888-10892. doi:10.1073/pnas.91.23.10888

Marder E, Bucher D. 2007. Understanding circuit dynamics using the stomatogastric nervous system of lobsters and crabs. Annu Rev Physiol 69:291-316. doi:10.1146/annurev.physiol.69.031905.161516

Marder E, Bucher D, Schulz DJ, Taylor AL. 2005. Invertebrate central pattern generation moves along. Curr Biol. doi:10.1016/j.cub.2005.08.022

McCabe BD, Marqués G, Haghighi AP, Fetter RD, Crotty ML, Haerry TE, Goodman CS, O'Connor MB. 2003. The BMP homolog Gbb provides a retrograde signal that regulates synaptic growth at the Drosophila neuromuscular junction. Neuron 39:241-254. doi:10.1016/S0896-6273(03)00426-4

Meyrand P, Moulins M. 1986. Myogenic oscillatory activity in the pyloric rhythmic motor system of Crustacea. J Comp Physiol A 158:489-503. doi:10.1007/BF00603795

Michailova AP, Belik ME, McCulloch AD. 2004. Effects of magnesium on cardiac excitationcontraction coupling. J Am Coll Nutr 23:514S-517S. doi:10.1080/07315724.2004.10719392

Milakovic M, Ormerod KG, Klose MK, Mercier AJ. 2014. Mode of action of a Drosophila FMRFamide in inducing muscle contraction. J Exp Biol 217. doi:10.1242/jeb.096941

Miller RN, Rinzel J. 1981. The dependence of impulse propagation speed on firing frequency, dispersion, for the Hodgkin-Huxley model, Biophysical Journal. doi:10.1016/S0006- 
Newman ZL, Hoagland A, Aghi K, Worden K, Levy SL, Son JH, Lee LP, Isacoff EY. 2017. Input-Specific Plasticity and Homeostasis at the Drosophila Larval Neuromuscular Junction. Neuron 93:1388-1404.e10. doi:10.1016/j.neuron.2017.02.028

Nusbaum MP, Blitz DM, Marder E. 2017. Functional consequences of neuropeptide and smallmolecule co-transmission. Nat Rev Neurosci 18:389-403. doi:10.1038/nrn.2017.56

Ormerod KG, Hadden JK, Deady LD, Mercier AJ, Krans JL. 2013. Action of octopamine and tyramine on muscles of Drosophila melanogaster larvae. J Neurophysiol 110. doi:10.1152/jn.00431.2013

Ormerod KG, Jung JH, Mercier AJ. 2018. Modulation of neuromuscular synapses and contraction in Drosophila 3rd instar larvae. J Neurogenet. doi:10.1080/01677063.2018.1502761

Ormerod KG, LePine OK, Bhutta MS, Jung J, Tattersall GJ, Mercier AJ. 2016. Characterizing the physiological and behavioral roles of proctolin in Drosophila melanogaster. $J$ Neurophysiol 115:568-580. doi:10.1152/jn.00606.2015

Ormerod KG, Lepine OK, Bhutta MS, Jung JH, Tattersall GJ, Joffre Mercier A. 2015. Characterizing the physiological and behavioral roles of proctolin in drosophila melanogaster. J Neurophysiol 115. doi:10.1152/jn.00606.2015

Picciotto MR, Higley MJ, Mineur YS. 2012. Acetylcholine as a Neuromodulator: Cholinergic Signaling Shapes Nervous System Function and Behavior. Neuron. doi:10.1016/j.neuron.2012.08.036

Ranatunga KW. 2018. Temperature effects on force and actin-myosin interaction in muscle: A look back on some experimental findings. Int J Mol Sci. doi:10.3390/ijms19051538

Reite OB. 1972. Comparative physiology of histamine. Physiol Rev. doi:10.1152/physrev.1972.52.3.778

Robbins J. 1959. The excitation and inhibition of crustacean muscle by amino acids. $J$ Physiol 
148:39-50. doi:10.1113/jphysiol.1959.sp006272

785

786

787

788

789

790

791

792

793

794

795

796

797

798

799

800

801

802

803

804

805

806

807

808

809

Roche JP, Packard MC, Moeckel-Cole S, Budnik V. 2002. Regulation of synaptic plasticity and synaptic vesicle dynamics by the PDZ protein scribble. J Neurosci 22:6471-6479. doi:10.1523/jneurosci.22-15-06471.2002

Rohrbough J, Pinto S, Mihalek RM, Tully T, Broadie K. 1999. latheo, a Drosophila gene involved in learning, regulates functional synaptic plasticity. Neuron 23:55-70. doi:10.1016/S0896-6273(00)80753-9

Saraswati S, Fox LE, Soll DR, Wu C-F. 2004. Tyramine and octopamine have opposite effects on the locomotion of Drosophila larvae. J Neurobiol 58:425-41. doi:10.1002/neu.10298

Schwarz O, Bohra AA, Liu X, Reichert H, Vijayraghavan K, Pielage J. 2017. Motor control of Drosophila feeding behavior. Elife 6. doi:10.7554/eLife.19892

Selverston AI. 2010. Invertebrate central pattern generator circuits. Philos Trans R Soc Lond B Biol Sci 365:2329-45. doi:10.1098/rstb.2009.0270

Selverston AI. 1980. Are central pattern generators understandable? Behav Brain Sci 3:535-540. doi:10.1017/S0140525X00006580

Shiels HA, Vornanen M, Farrell AP. 2002. Temperature dependence of cardiac sarcoplasmic reticulum function in rainbow trout myocytes. J Exp Biol 205:3631-3639.

Singhania A, Grueber WB. 2014. Development of the embryonic and larval peripheral nervous system of Drosophila. Wiley Interdiscip Rev Dev Biol 3:193-210. doi:10.1002/wdev.135

Song W, Onishi M, Lily YJ, Yuh NJ. 2007. Peripheral multidendritic sensory neurons are necessary for rhythmic locomotion behavior in Drosophila larvae. Proc Natl Acad Sci U S A 104:5199-5204. doi:10.1073/pnas.0700895104

Swann JW, Sinback CN, Pierson MG, Carpenter DO. 1982. Dopamine produces muscle contractions and modulates motoneuron-induced contractions in Aplysia gill. Cell Mol Neurobiol 2:291-308. doi:10.1007/bf00710850

Terry RL, Kaneb HM, Wells DJ. 2014. Poloxomer 188 Has a Deleterious Effect on Dystrophic 
Van Harreveld A, Mendelson M. 1959. Glutamate-induced contractions in crustacean muscle. $J$ Cell Comp Physiol 54:85-94. doi:10.1002/jcp.1030540109

Vornanen M. 2016. The temperature dependence of electrical excitability in fish hearts. $J$ Exp Biol. doi:10.1242/jeb.128439

Wang G, Kawai M. 2001. Effect of temperature on elementary steps of the cross-bridge cycle in rabbit soleus slow-twitch muscle fibres. J Physiol 531:219-234. doi:10.1111/j.1469-

Wang M, Tashiro M, Berlin JR. 2004. Regulation of L-type calcium current by intracellular magnesium in rat cardiac myocytes. $J$ Physiol 555:383-396. presynaptic release and synapse-specific growth. Science 310:858-63. doi:10.1126/science.1117541 
842

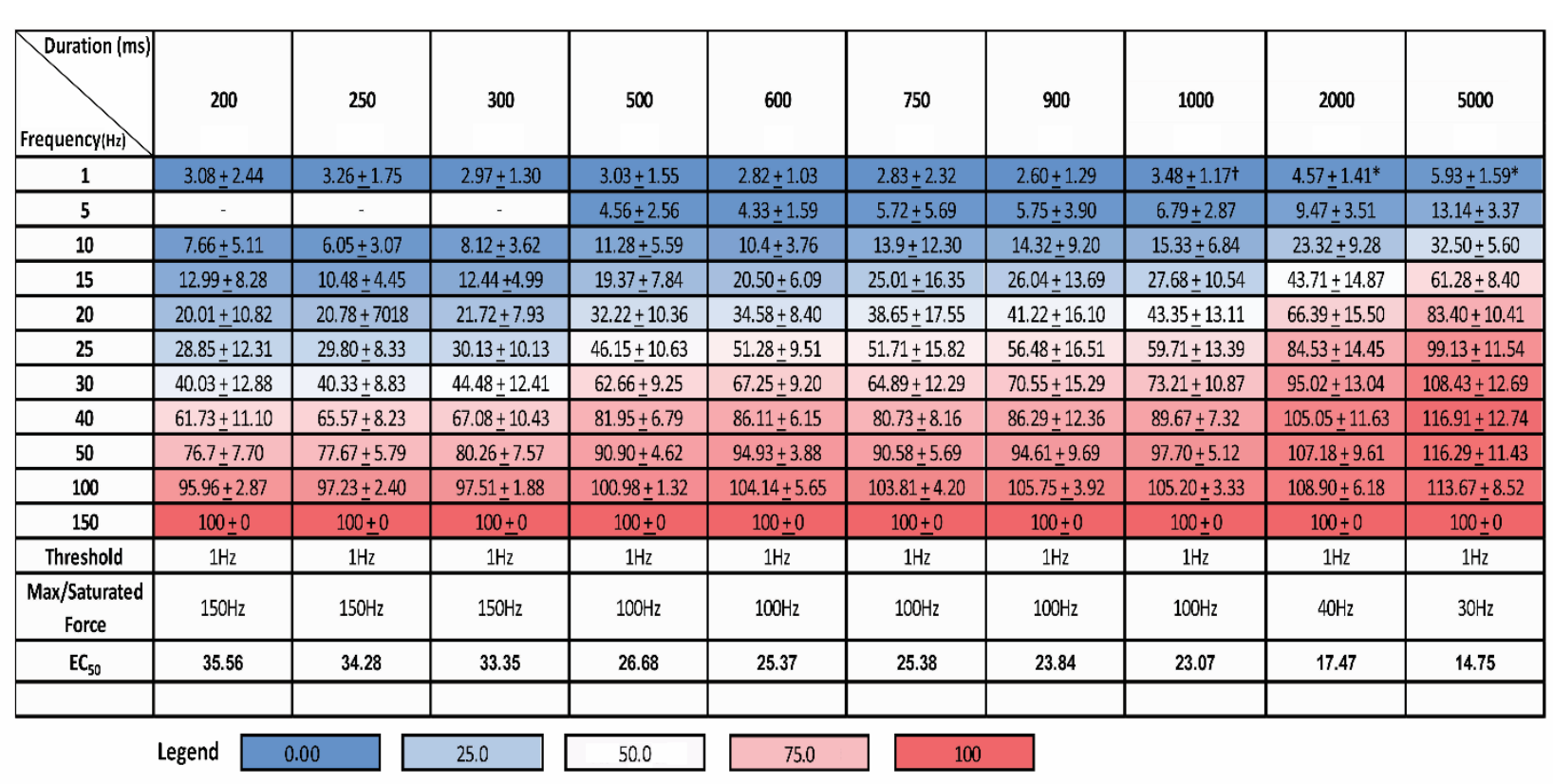

Table 1: Force-frequency values for 10 different stimulus durations calculated as a percentage of the contraction force elicited from $150 \mathrm{~Hz}$ stimulation. Thresholds indicate the stimulation frequency needed to elicit a visible and quantifiable contraction trace. Maximum or saturation force value indicates the frequency required to elicit a contraction that is equal in magnitude or exceeds the contraction force value obtained using $150 \mathrm{~Hz}$ stimulation. The $\mathrm{EC}_{50}$ denotes the stimulation frequency required to generate a contraction that is $50 \%$ of maximal force value obtained using $150 \mathrm{~Hz}$, calculated from the forcefrequency plots using GraphPad Prism.

843

844 


\section{Figure legends:}

852 Figure 1. Muscle contraction dynamics from $3^{\text {rd }}$ instar larvae. A) 3D schematic of the experimental setup highlighting the force transducer, temperature-controlled holder with perfusion system, suction electrode, and $3^{\text {rd }}$ instar larva. B) Representative trace from a single contraction elicited at $40 \mathrm{~Hz}$ for $750 \mathrm{~ms}$. Crosshairs indicate metrics derived from each contraction used for subsequent analyses. C) Percent of initial contraction force for steady-state recordings from control Canton $\mathrm{S}$ larvae elicited with $40 \mathrm{~Hz}$ stimulation for $600 \mathrm{~ms}$ every $15 \mathrm{~s}$. Circles denote individual replicate recordings plotted as a percentage change in contraction amplitude compared to the initial contraction. N=9-11. D) Representative intracellular voltage recording from muscle fiber 6 demonstrating CPG firing patterns from a larva with the CNS left intact. The dashed box in the upper trace is expanded below. E) Larval motoneuron stimulation paradigm used to generate dynamic force-frequency recordings for muscle contraction from initial threshold through saturation $(1-150 \mathrm{~Hz})$. Stimulus number was kept constant at 25. F) Six replicate contractions from each stimulation frequency in panel $\mathrm{E}$ were averaged and plotted with the associated 95\% CI. G) Results using dynamic force-frequency motoneuron stimulation paradigm where stimulus duration was kept constant at $600 \mathrm{~ms} \mathbf{H}) 6$ replicate contractions from each stimulation frequency in panel $\mathrm{G}$ were averaged and plotted with $95 \%$ CI. I) Muscle force versus stimulation frequency from each of the stimulation paradigms depicted in E-H is shown (25 stimuli: intraburst duration consisted of 25 stimuli at each stimulus frequency, $\mathrm{N}=10,6$ replicate contractions were elicited at each stimulation frequency and averaged for each animal. $600 \mathrm{~ms}$ duration: intraburst duration at each frequency was $600 \mathrm{~ms}$ in duration, 6 replicate contractions were elicited at each stimulation frequency and averaged for each animal, $\mathrm{N}=20$ ).

Figure 2. Effects of stimulus duration or frequency on muscle contraction. A) Cumulative forcefrequency plots showing the effects of varying the stimulus duration from $200 \mathrm{~ms}$ to $5000 \mathrm{~ms}(\mathrm{~N}=7-10)$. B) Representative traces for $25 \mathrm{~Hz}$ stimulation for 200, 300, 600, 900, and $2000 \mathrm{~ms}$ stimulus duration. C) Maximal force generated from a $150 \mathrm{~Hz}$ stimulation frequency from each replicate larva for each of the 13 different stimulation durations. D) Representative single contraction traces from 200, 300, 600, 900, and $2000 \mathrm{~ms}$ duration stimuli at $150 \mathrm{~Hz}$.

Figure 3. Muscle force generation is independent of $3^{\text {rd }}$ instar larval size. A top) Schematic representation of a cross-section through a $3^{\text {rd }}$ instar larval abdominal segment highlighting the main muscles contributing to longitudinal larval peristalsis. D-V represents the dorsal-ventral axis. Scale bar below indicates how width measurements were taken. A bottom) Schematic representation of a dissected larva highlighting the main longitudinal muscles that contributes to larval peristalsis. Scale bar to the right indicates how length measurements were determined. B) Summary of maximal force values obtained corresponding maximal force values obtained from 100 animals. Neither parameter correlates with maximal force generated (two-tailed Pearson's correlation; Width: $\mathrm{r}=0.01462, \mathrm{P}=0.8906$; length: $\mathrm{r}=-0.009, \mathrm{P}=0.9325$ ). 
Figure 4. Similar contraction properties of ventral, dorsal and lateral muscle groups. A) Top: Schematic representation of cross-sections through larvae from three different orientations highlighting the dominant muscles contributing to force measurements in each condition. Bottom: Dissected larvae and the corresponding muscle configuration for each orientation. Blue denotes muscles along the dorsal axis, green denotes muscles along the ventral axis, and red denotes muscles along the medial axis. B) Cartoon depicting a single abdominal hemisegment highlighting muscle fiber number. C) Muscle force-frequency curves for each of the larval dissection orientations, indicating muscle contraction force-frequency is similar across the different fibers. D) Maximal force generated from a $150 \mathrm{~Hz}$ stimulus at $600 \mathrm{~ms}$ duration in each of the three different orientations shows no significant differences (One-way ANOVA, N=8, $\mathrm{P}=0.4037, \mathrm{~F}=0.915)$.

Figure 5. Effects of external $\mathrm{Ca}^{2+}$ and $\mathrm{Mg}^{2+}$ on muscle contraction force. A) Force-frequency curves generated using a $600 \mathrm{~ms}$ duration stimulus for two physiological salines, HL3 $\left(20 \mathrm{mM} \mathrm{Mg}{ }^{2+}\right)$ and HL3.1 $\left(4 \mathrm{mM} \mathrm{Mg}{ }^{2+}\right)$ in $0.1 \mathrm{mM}\left[\mathrm{Ca}^{2+}\right]_{\mathrm{o}}, 0.25 \mathrm{mM}\left[\mathrm{Ca}^{2+}\right]_{0}, 0.5 \mathrm{mM}\left[\mathrm{Ca}^{2+}\right]_{\mathrm{o}}$, and $1.0 \mathrm{mM}\left[\mathrm{Ca}^{2+}\right]_{\mathrm{o}}$. B) Halfmaximal stimulation frequency required to generate $50 \%$ of the maximal force observed for each stimulus duration, $\left[\mathrm{Ca}^{2+}\right]_{\mathrm{o}}$, and saline is shown. The data was obtained from force frequency curves generated using 200, 300, 600, and $900 \mathrm{~ms}$ stimulation duration for both physiological salines in 6 different $\left[\mathrm{Ca}^{2+}\right]_{\mathrm{o}}$. $\mathbf{C}$ Force values generated from single motoneuron stimuli in 7 different $\left[\mathrm{Ca}^{2+}\right]_{\mathrm{o}}$ in ) HL3, and . Inset: representative force traces from 1.0 and $2.0 \mathrm{mM}\left[\mathrm{Ca}^{2+}\right]_{0}$. D Force values generated from single motoneuron stimuli in 7 different $\left[\mathrm{Ca}^{2+}\right]_{0}$ in HL3.1. Inset: representative force traces from $0.25,0.5$, and $2.0 \mathrm{mM}\left[\mathrm{Ca}^{2+}\right]_{\mathrm{o}}$. E EJPs amplitude values obtained from the 7 different $\left[\mathrm{Ca}^{2+}\right]_{\mathrm{o}}$ in HL3.1.

Figure 6. Effects of temperature on muscle contraction force. A) Force of muscle contraction as a function of temperature. Contractions were elicited using a $40 \mathrm{~Hz} 600 \mathrm{~ms}$ duration stimulus given continuously throughout the experiment as temperature was varied. B) Color-coded individual traces from a representative experiment depicting the effects of temperature on contraction amplitude. C) Histogram showing the effect of temperature on muscle contractions elicited using $25 \mathrm{~Hz}$ or $40 \mathrm{~Hz}$ stimulation for 600 ms duration. D) Effects of thermal acclimation on muscle contraction force assayed in larvae from stocks reared for 3 generations at 22,25 , or $29^{\circ} \mathrm{C}$.

Figure 7. Effects of synaptic mutants on muscle contractile force. A) Maximal contraction force generated for control Canton S, Cpx null mutants $\left(c p x^{S H 1}\right), G b b$ null mutants $\left(G b b^{1} / G b b^{2}\right)$, Sytl null mutants $\left(S y t 1^{A D 4} / S y t 1^{N 13}\right)$ and Syt4 null mutants $\left(S y t 4^{B A 1}\right)$. B) The magnitude of force generated from a single stimulus from each genotype is shown. One-way ANOVA, $* * \mathrm{p}<0.01, * * * \mathrm{p}<0.001$.

Figure 8. Amplitude of larval contractions plotted as a function of time using a steady-state motoneuron stimulation at $40 \mathrm{~Hz}$ for $600 \mathrm{~ms}$ duration every 15s. Experiments were 15-20 minutes in duration with a constant perfusion of saline for 5 minutes followed by addition of A) Leucokinin, B) GABA, C) acetylcholine, D) PACAP27, E) histamine, F) dopamine, or G) TPAEDFMRFa, followed by a 5-10 min saline washout. H) Dose-dependent effects of TPAEDFMRFa on muscle contraction using either the steady-state or dynamic motoneuron stimulation paradigm. I) Dose-dependent effects of TPAEDFMRFa using the dynamic motoneuron stimulation paradigm. Inset: control (blue) vs. TPAEDFMRFa (pink) at 10 $\mathrm{Hz}$ and $40 \mathrm{~Hz}$ stimulation. 
930 Figure 9. Analysis of the TPAEDFMRFa pathway for enhancing contractile force at the NMJ. A) Force931 frequency plots for the effectiveness of TPAEDFMRFa on muscle contraction force in Canton $\mathrm{S}$ versus 932 larvae expressing FMRFa receptor UAS-RNAi presynaptically (Elav-GAL4), postsynaptically (Mef2933 GAL4) or in both compartments. B) Force-frequency plots for the effectiveness of TPAEDFMRFa on 934 muscle contraction force in Canton S versus larvae expressing Myosuppressin receptor 1 or 2 UAS-RNAi 935 presynaptically (Elav-GAL4), postsynaptically (Mef2-GAL4) or in both compartments.

936

937

938

939

940

941

942

943

944

945

946

947

948

949

950 


\section{Supplemental Table:}

953 Supplemental Table 1: $\mathrm{EC}_{50}$ calculations for TPAEDFMRFa's effectiveness for increasing the force of 954 contractions. For each frequency the maximum force increase (typically from $10^{-5} \mathrm{M}$ ) observed following 955 TPAEDFMRFa was also calculated.

\begin{tabular}{|l|l|l|}
\hline \multicolumn{2}{|l|}{ [EC50] for TPAEDFMRFa } & Maximum force increase (\%) \\
\hline 1 & $3.90 \times 10^{-8} \mathrm{M}$ & 115 \\
\hline 5 & $2.60 \times 10^{-8} \mathrm{M}$ & 183 \\
\hline 10 & $1.85 \times 10^{-8} \mathrm{M}$ & 156 \\
\hline 15 & $1.41 \times 10^{-8} \mathrm{M}$ & 130 \\
\hline 20 & $1.13 \times 10^{-8} \mathrm{M}$ & 114 \\
\hline 25 & $1.23 \times 10^{-8} \mathrm{M}$ & 91 \\
\hline 30 & $1.27 \times 10^{-8} \mathrm{M}$ & 72 \\
\hline 40 & $2.10 \times 10^{-8} \mathrm{M}$ & 39 \\
\hline 50 & $2.43 \times 10^{-8} \mathrm{M}$ & 34 \\
\hline 100 & $1.30 \times 10^{-8} \mathrm{M}$ & 21 \\
\hline 150 & $6.1 \times 10^{-9} \mathrm{M}$ & 20 \\
\hline
\end{tabular}

956

\section{Supplemental figure legends}

958 Supplemental Figure 1 (S1): Effects of external $\mathrm{Ca}^{2+}$ and $\mathrm{Mg}^{2+}$ on muscle contraction force. Force959 frequency curves generated using 200, 300, 600, and $900 \mathrm{~ms}$ duration stimuli for two physiological 960 salines, HL3 $\left(20 \mathrm{mM} \mathrm{Mg}^{2+}\right)$ and HL3.1 $\left(4 \mathrm{mM} \mathrm{Mg}^{2+}\right)$ in $0.1 \mathrm{mM}\left[\mathrm{Ca}^{2+}\right]_{\mathrm{o}}, 0.25 \mathrm{mM}\left[\mathrm{Ca}^{2+}\right]_{\mathrm{o}}, 0.5 \mathrm{mM}$ $961\left[\mathrm{Ca}^{2+}\right]_{\mathrm{o}}, 1.0 \mathrm{mM}\left[\mathrm{Ca}^{2+}\right]_{\mathrm{o}}$ and $2.0 \mathrm{mM}\left[\mathrm{Ca}^{2+}\right]_{\mathrm{o}}$. 

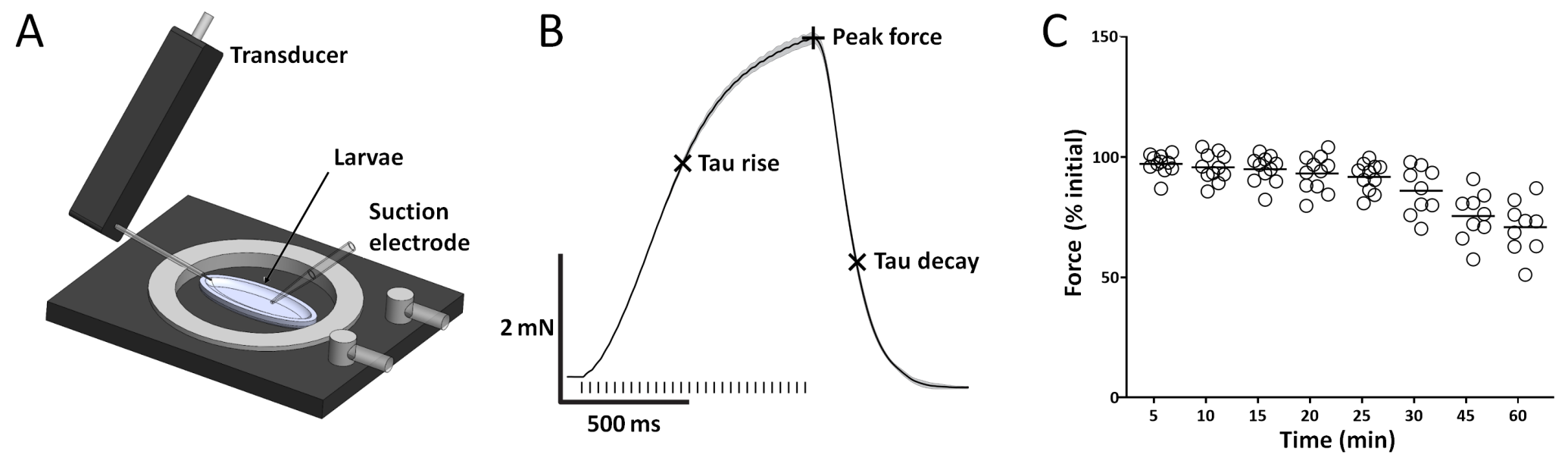

D

E
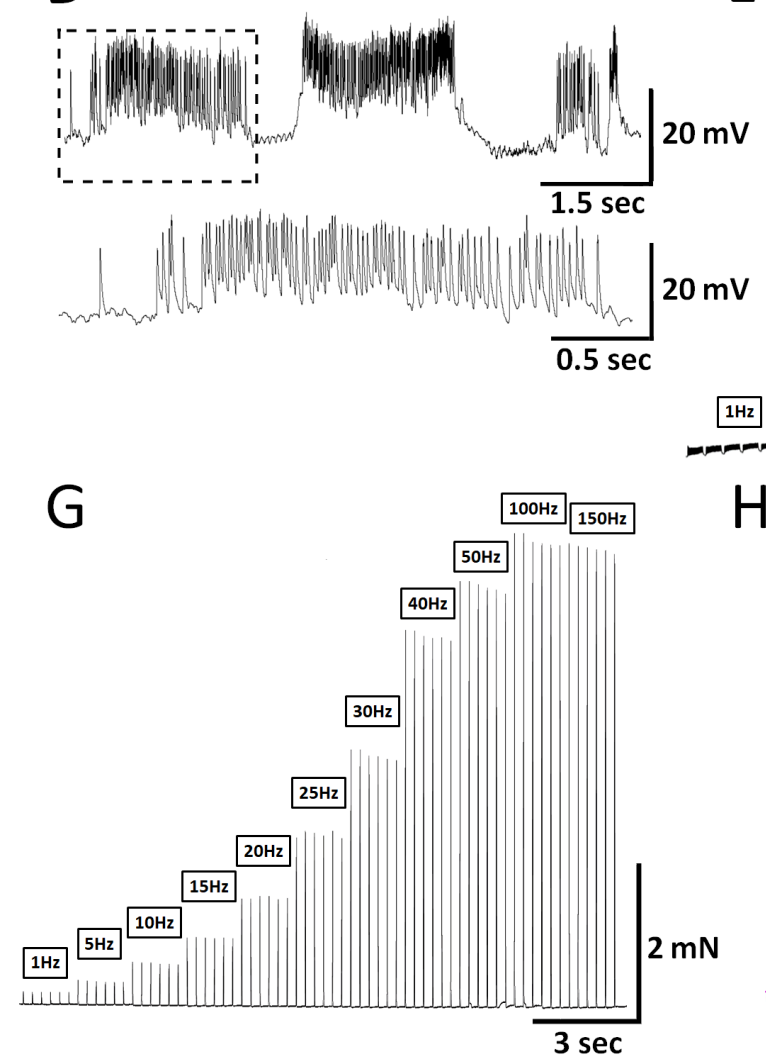

$20 \mathrm{mV}$

$10 \mathrm{~Hz}$

$2 \mathrm{~Hz} \frac{5 \mathrm{~Hz}}{5 \mathrm{~Hz}}$

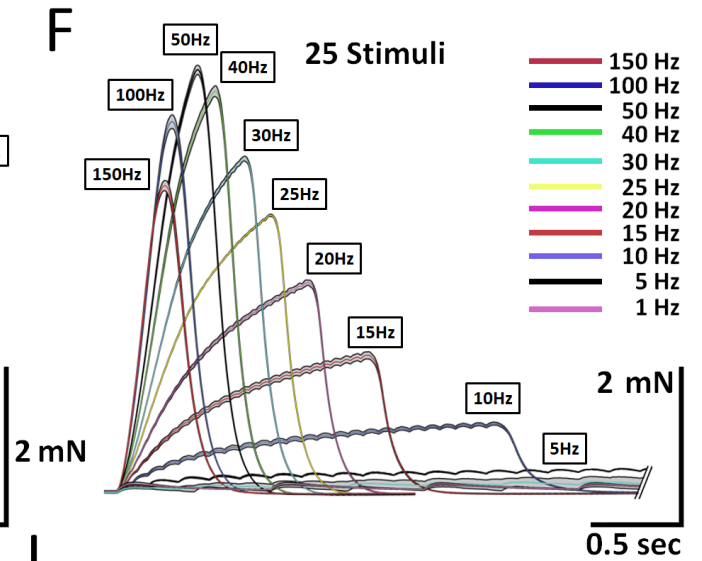

$\mathrm{H} \quad 600$ ms duration
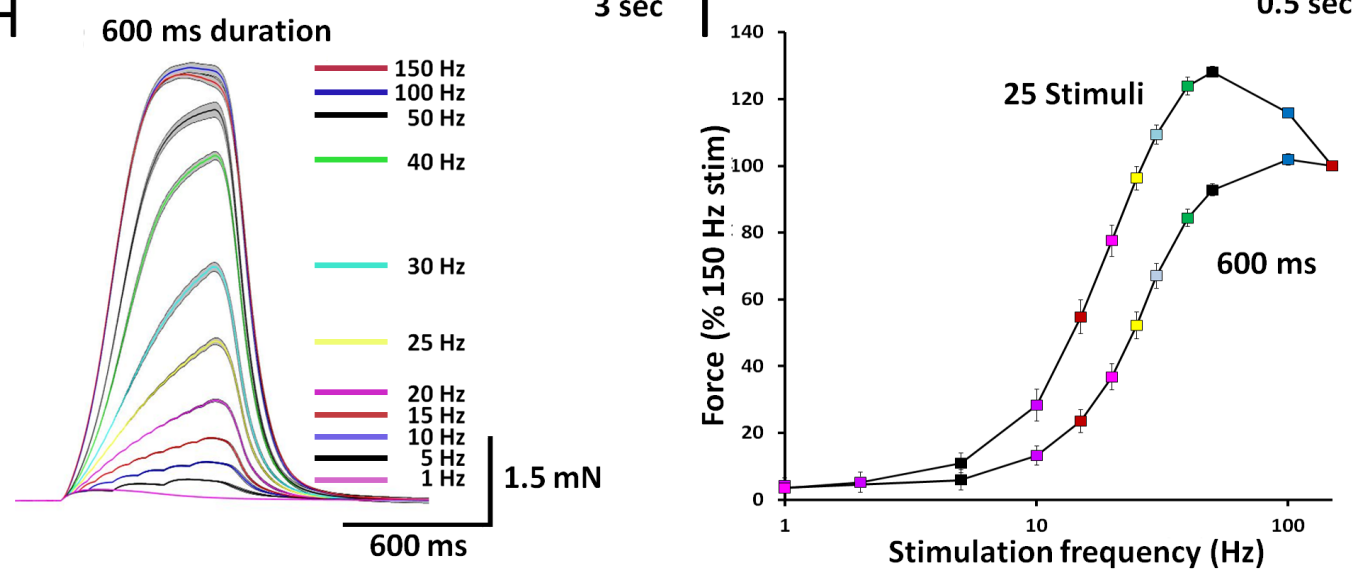


\section{A Stimulus duration (ms)}
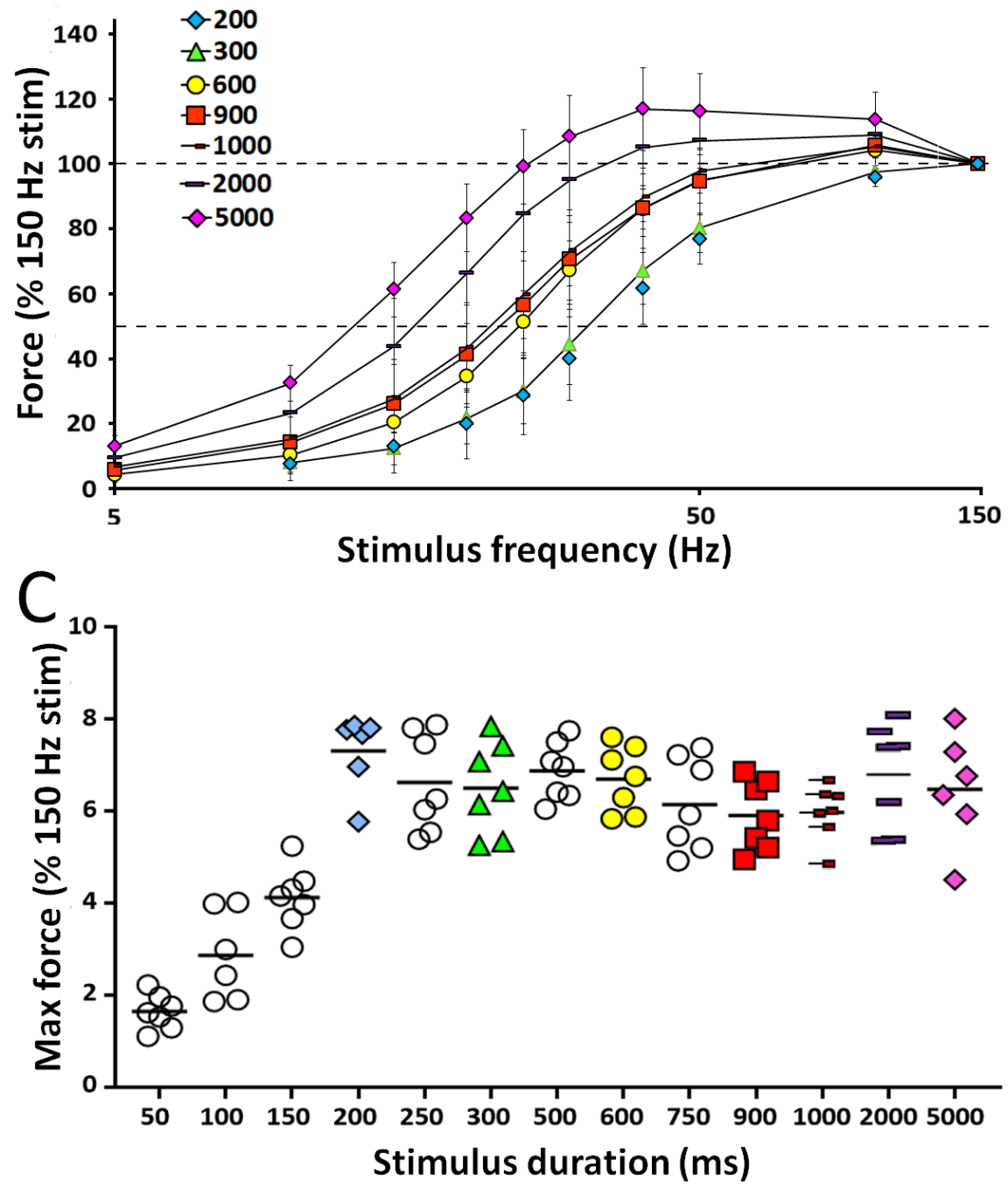

B
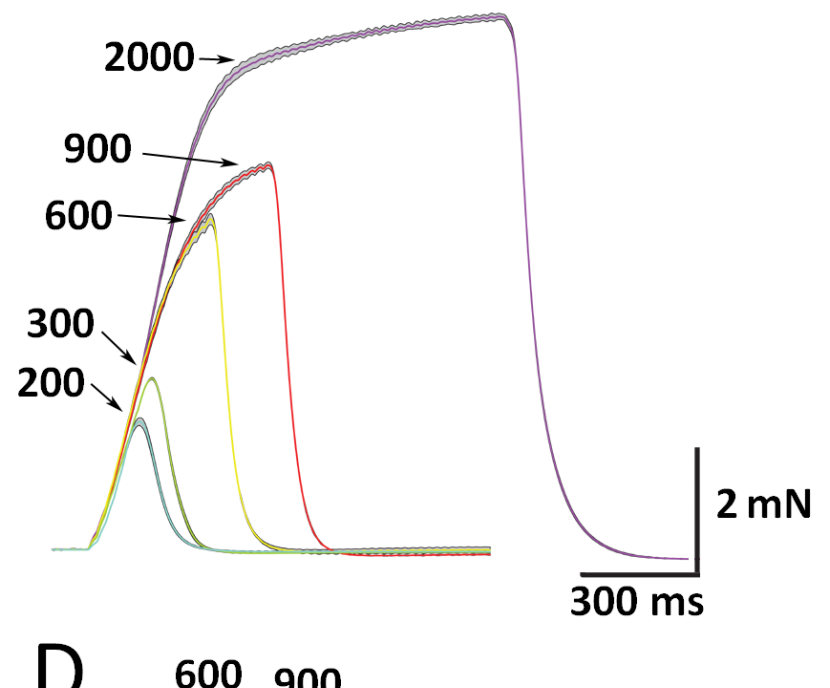

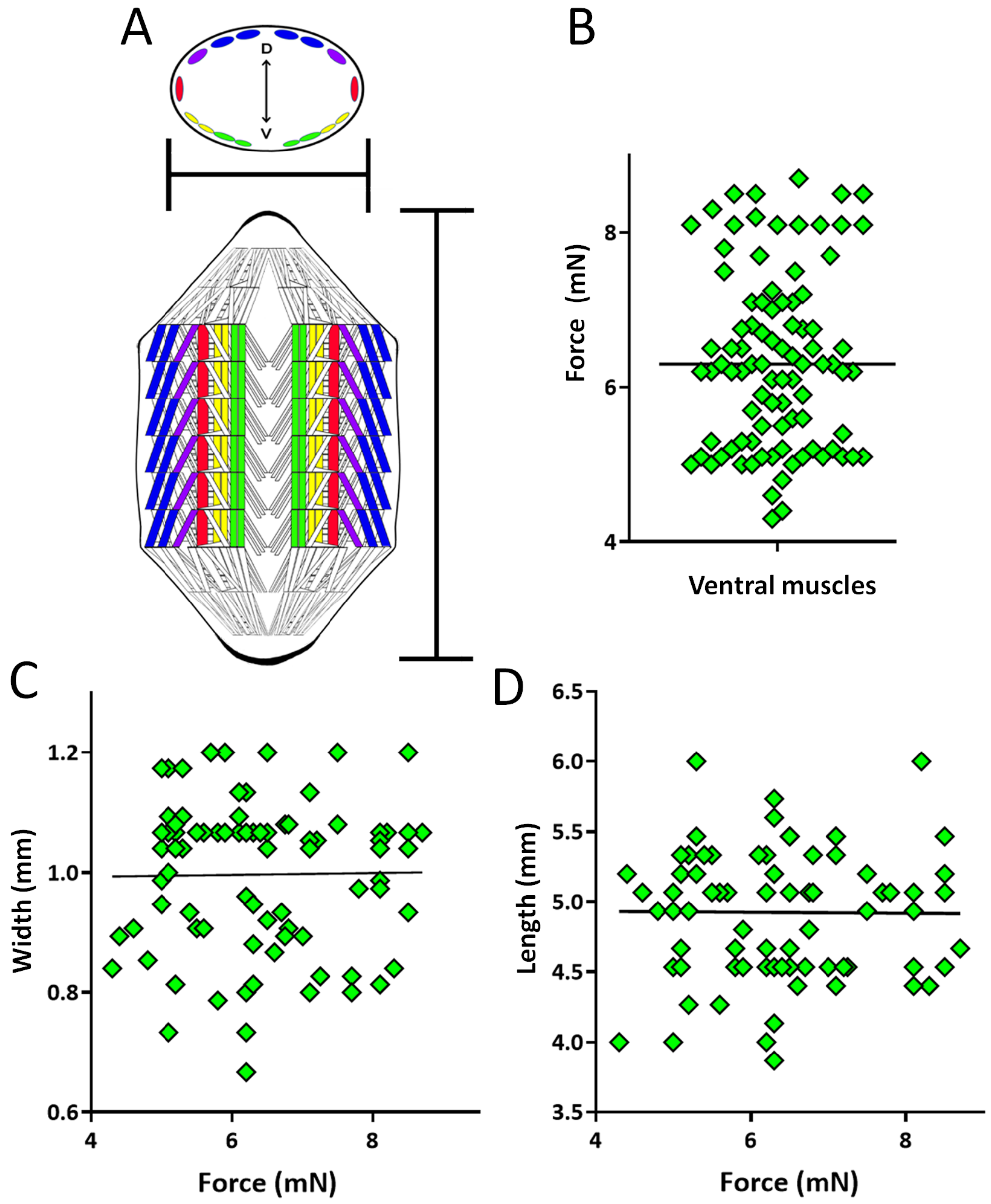
bioRxiv preprint doi: https://doi.org/10.1101/2020.07.09.196261; this version posted July 10,2020. The copyright holder for this preprint (which was not certified by peer review) is the author/funder, who has granted bioRxiv a license to display the preprint in perpetuity. It is made available under aCC-BY 4.0 International license.

A
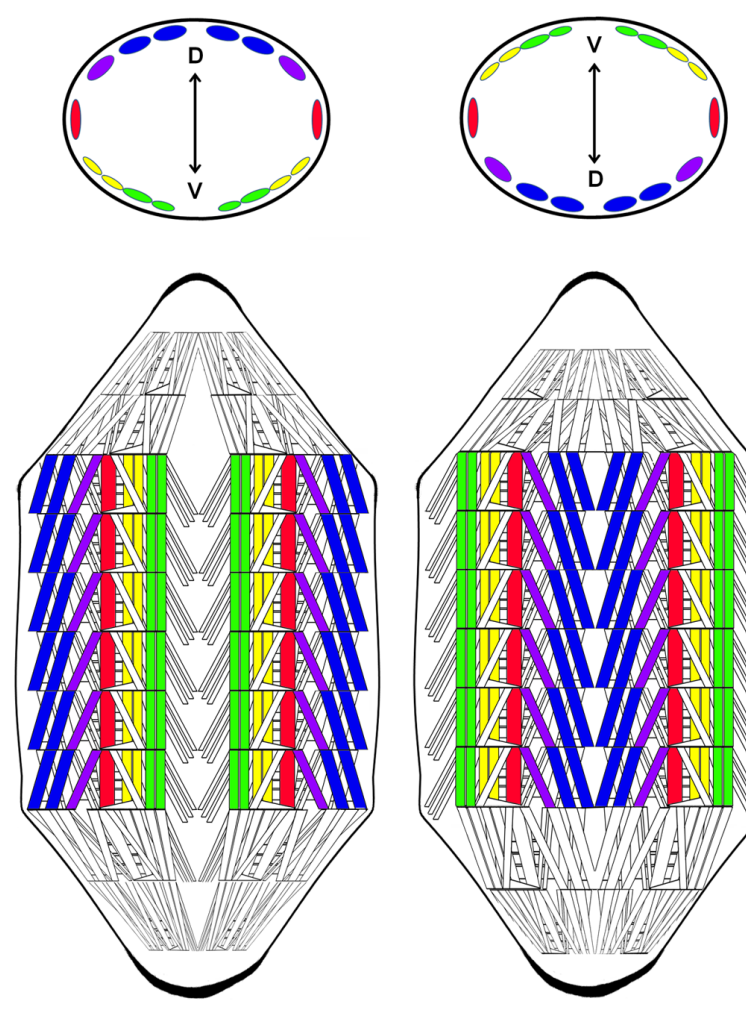

Ventral muscles

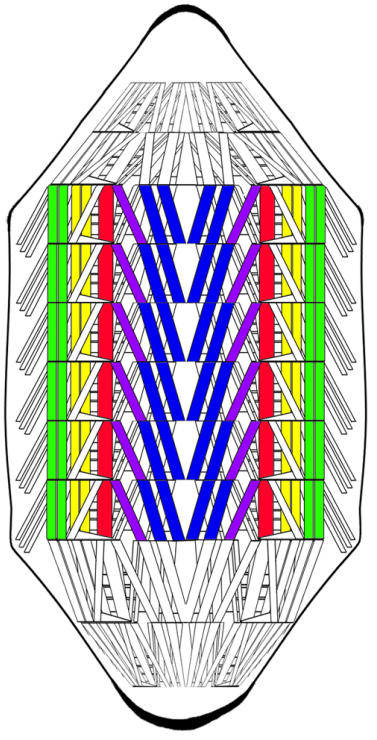

Dorsal muscles

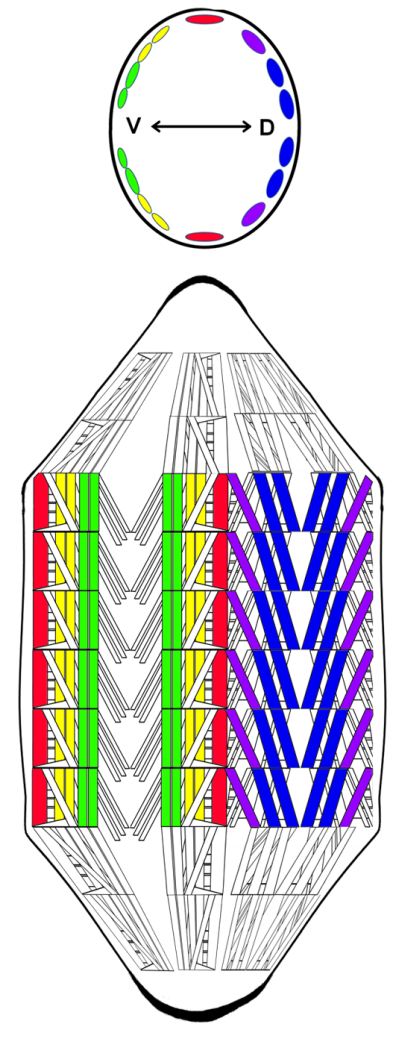

Lateral muscles

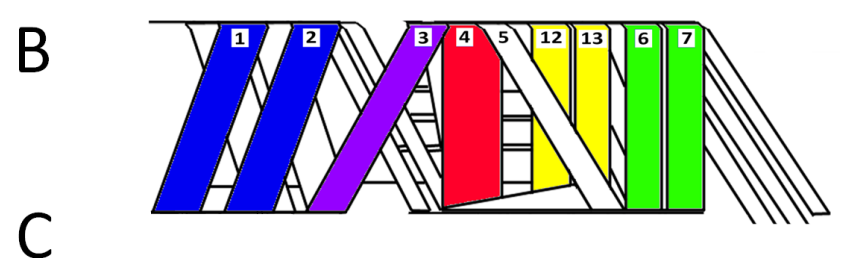

C

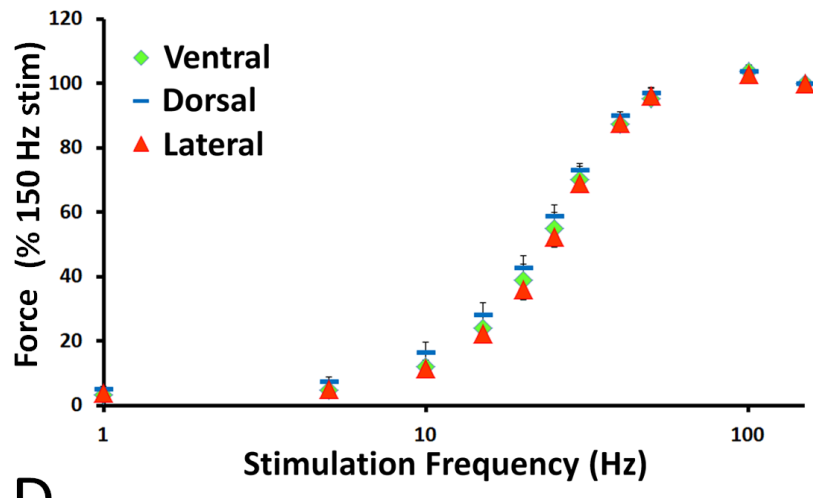

D

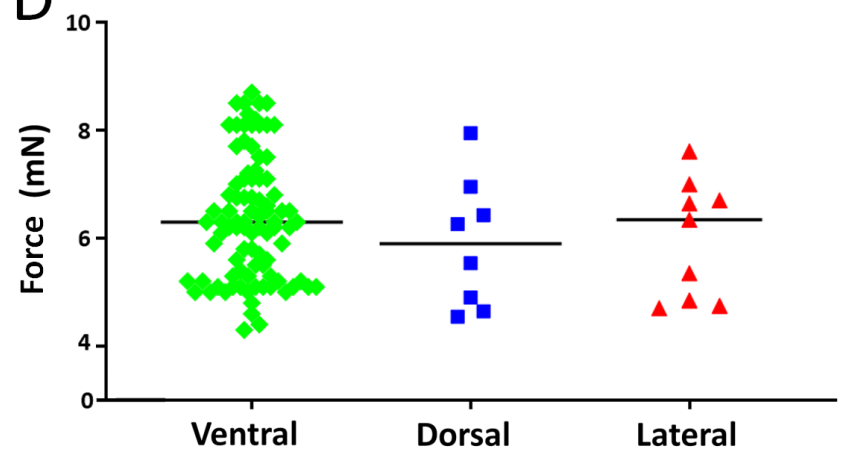


A
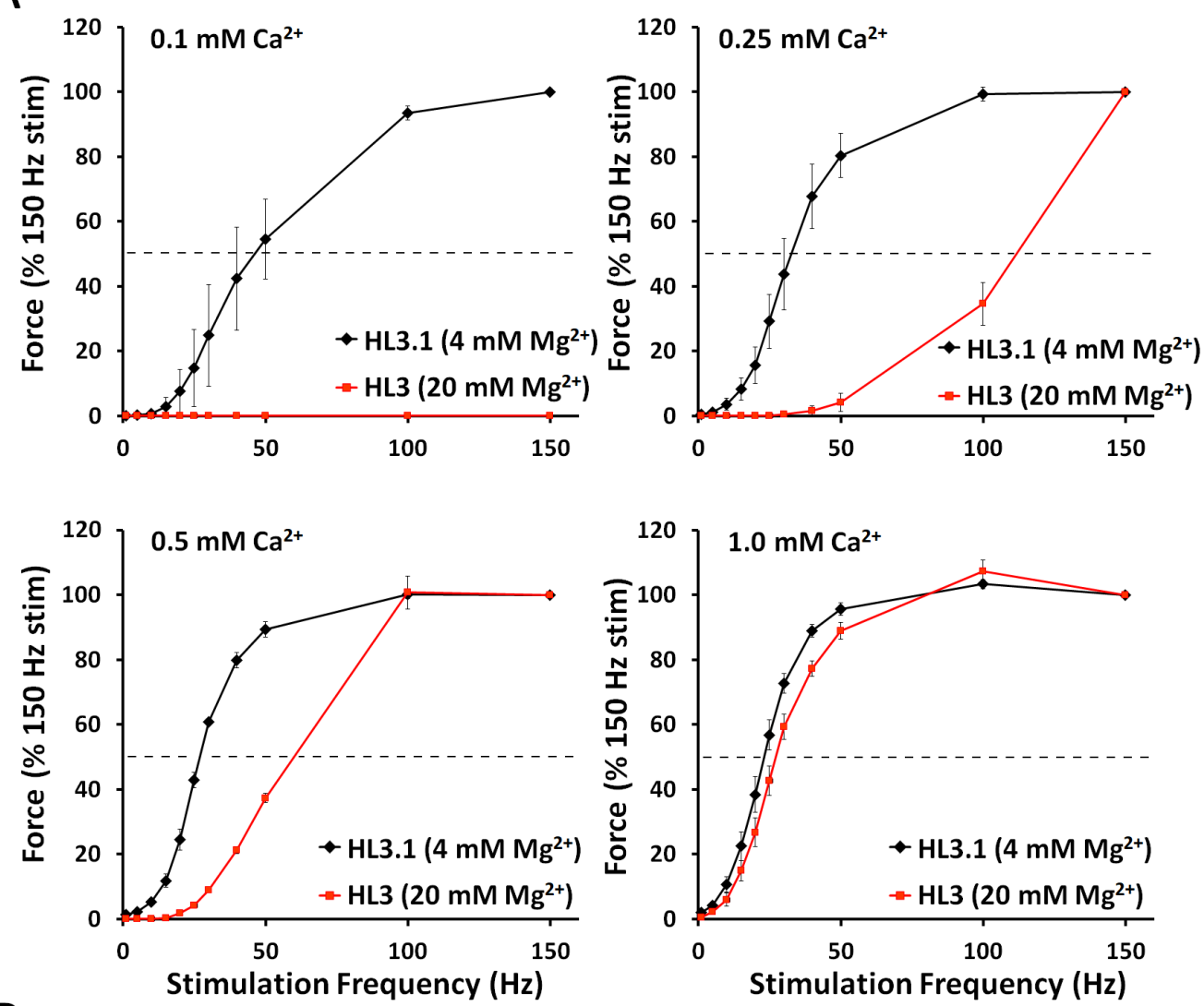

B

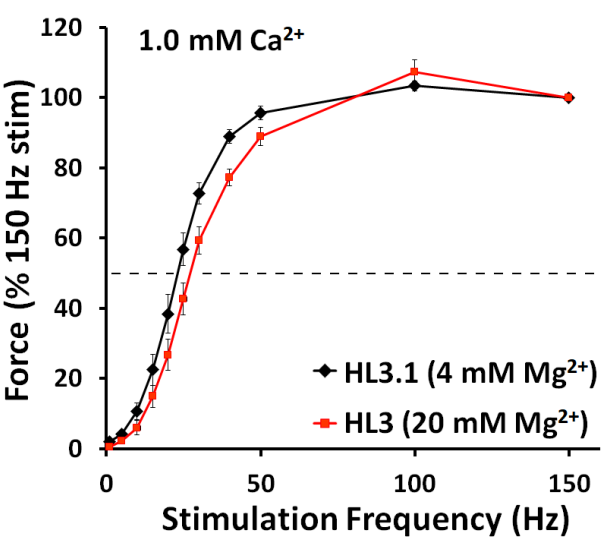

C
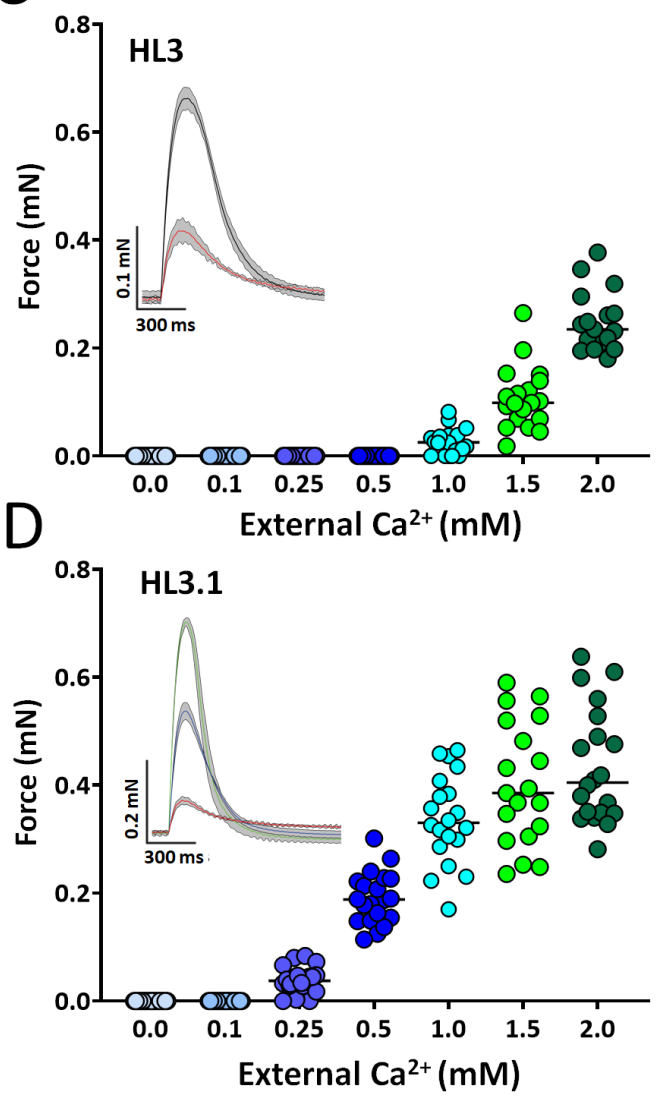

$E$

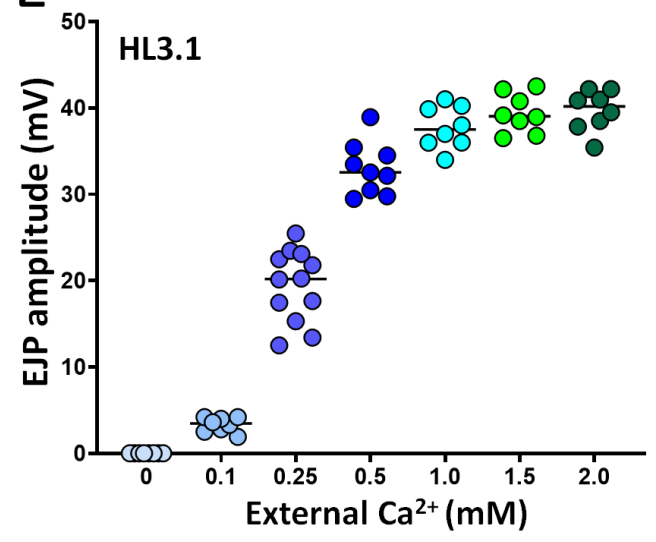


bioRxiv preprint doi: https://doi.org/10.1101/2020.07.09.196261; this version posted July 10, 2020. The copyright holder for this preprint (which was not certified by peer review) is the author/funder, who has granted bioRxiv a license to display the preprint in perpetuity. It is made available under aCC-BY 4.0 International license.

A

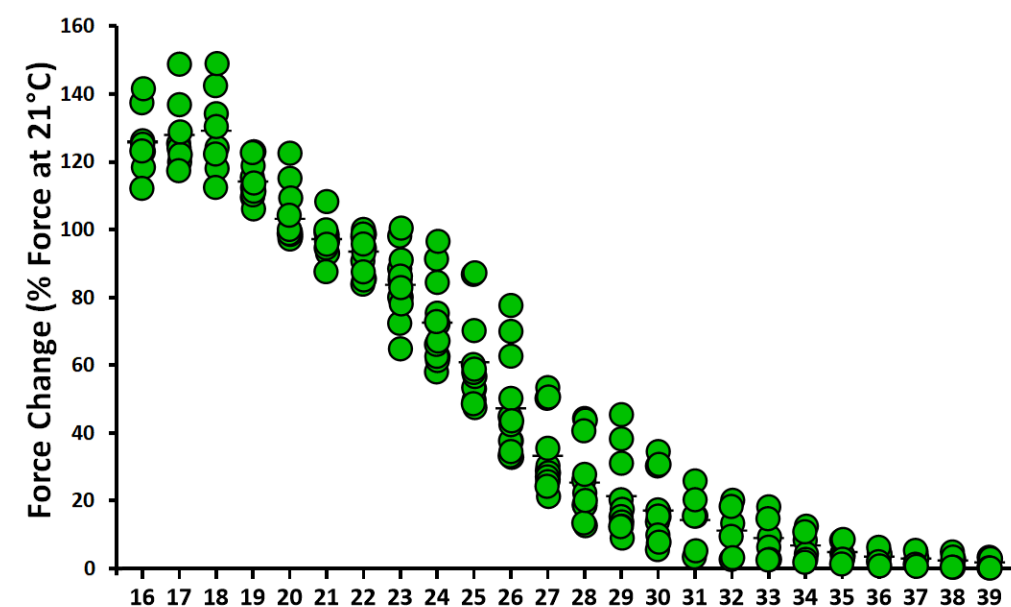

C

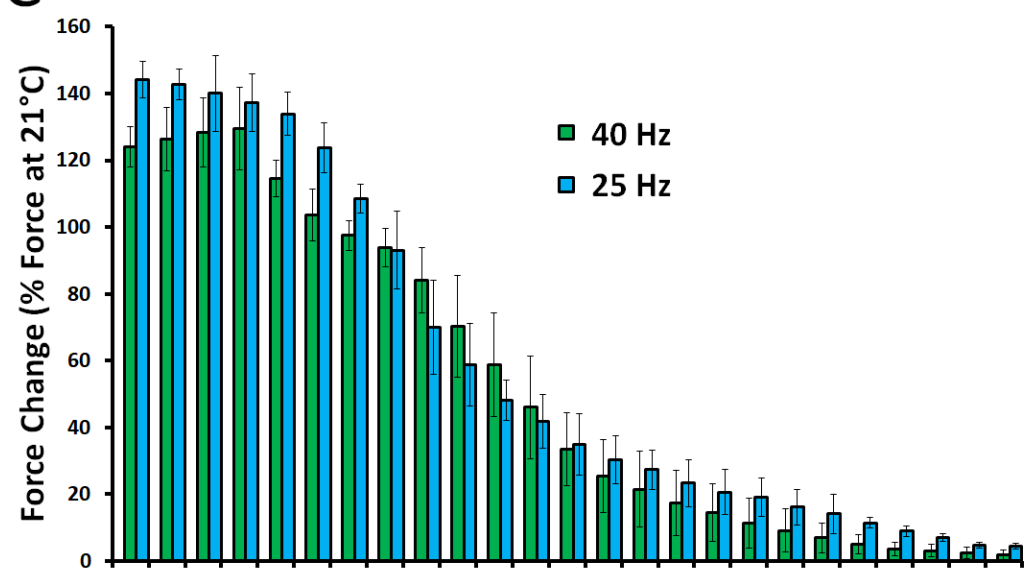

$\begin{array}{lllllllllllllllllllllllll}15 & 16 & 17 & 18 & 19 & 20 & 21 & 22 & 23 & 24 & 25 & 26 & 27 & 28 & 29 & 30 & 31 & 32 & 33 & 34 & 35 & 36 & 37 & 38 & 39\end{array}$ Temperature $\left({ }^{\circ} \mathrm{C}\right)$
B
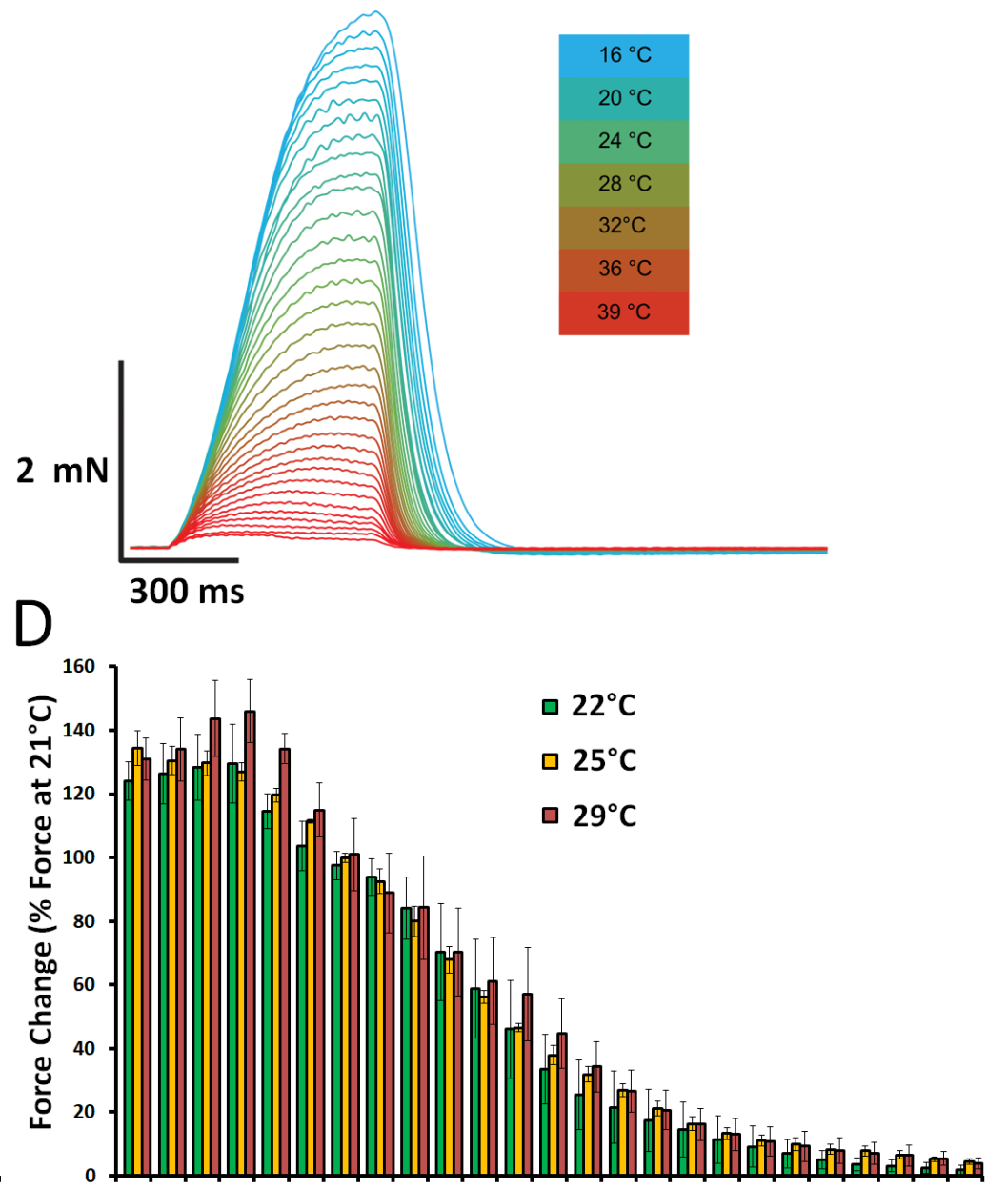

$\begin{array}{lllllllllllllllllllllllll}15 & 16 & 17 & 18 & 19 & 20 & 21 & 22 & 23 & 24 & 25 & 26 & 27 & 28 & 29 & 30 & 31 & 32 & 33 & 34 & 35 & 36 & 37 & 38 & 39\end{array}$ Temperature $\left({ }^{\circ} \mathrm{C}\right)$ 
A

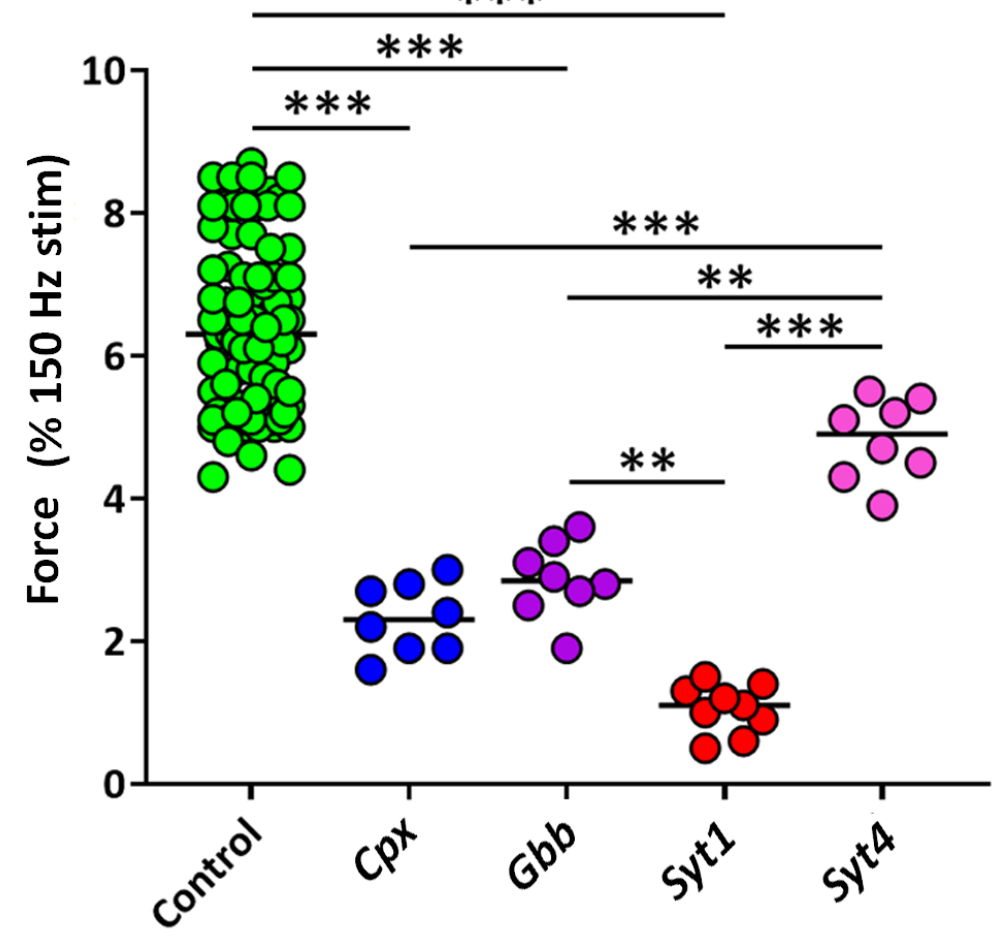

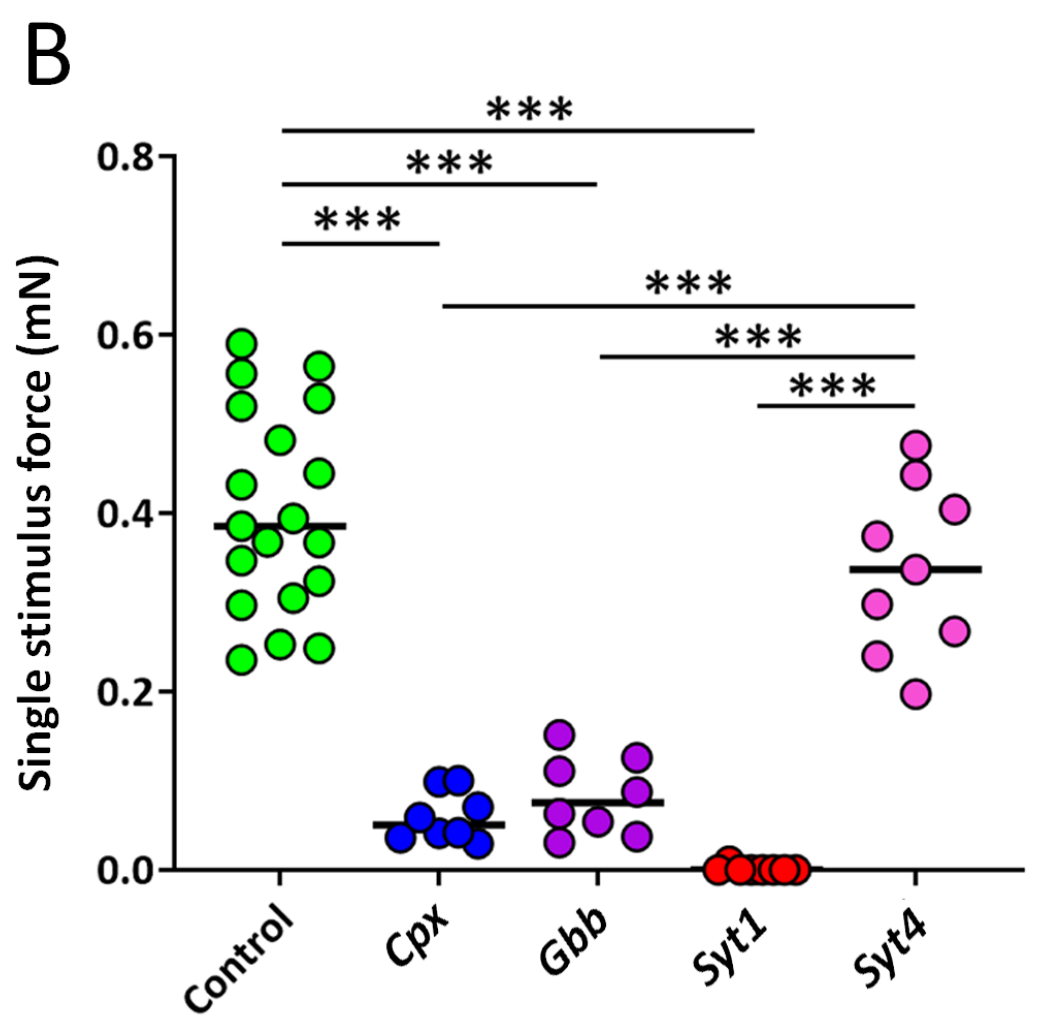



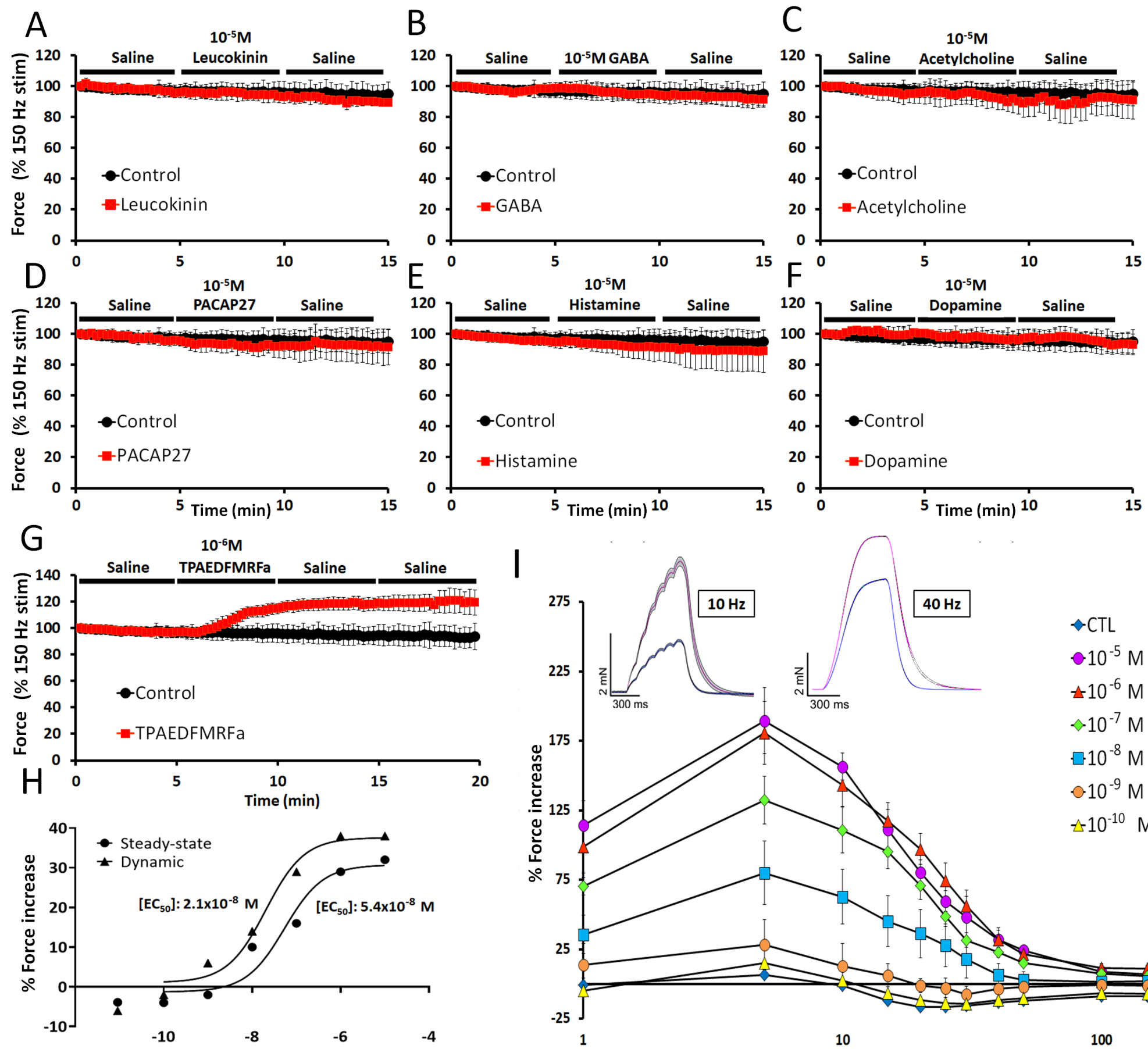

Peptide concentration (M)

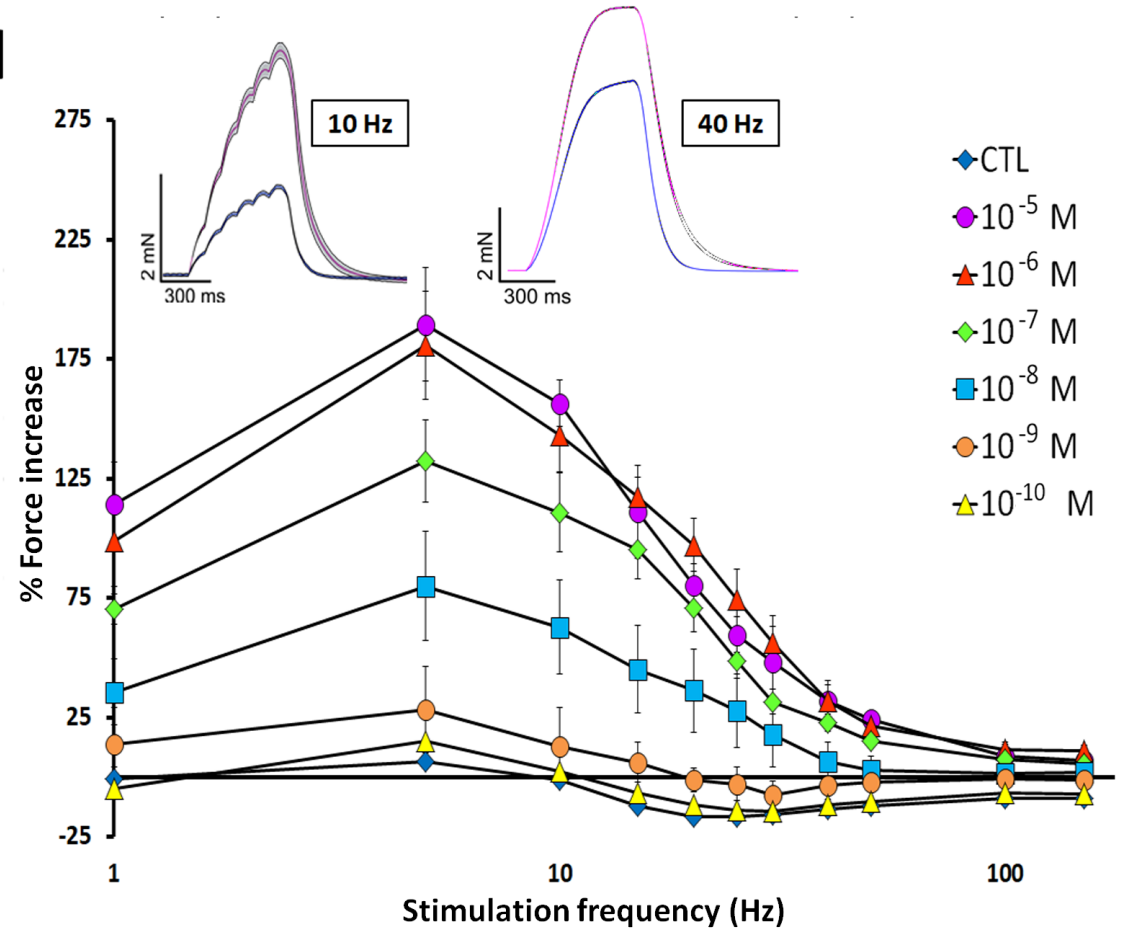




\section{A}

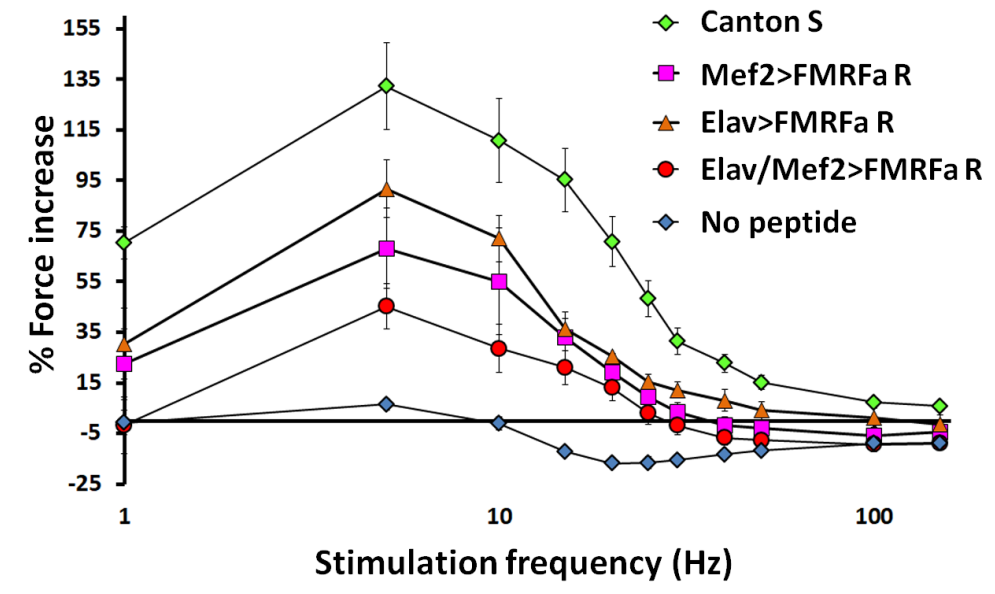

B

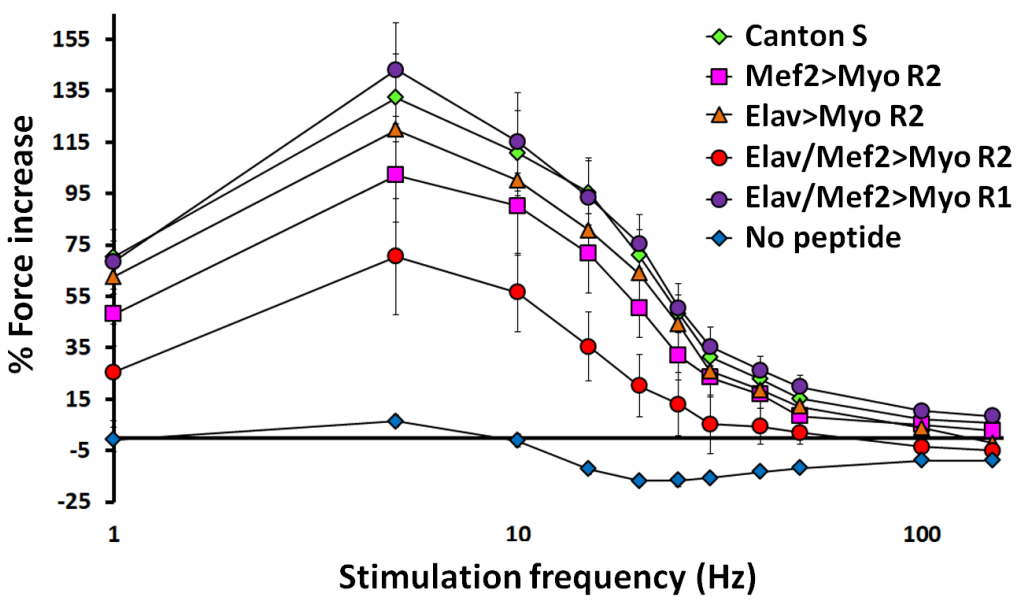


